\title{
Migração familiar, trabalho infantil e ciclo intergeracional da pobreza no estado de São Paulo
}

\author{
Natalia Ferreira-Batista \\ Departamento de Economia \\ Universidade de Săo Paulo/Ribeirāo Preto FEARP-USP \\ Maria Cristina Cacciamali \\ Departamento de Economia \\ Universidade de São Paulo FEA-USP
}

\section{Palavras-chave}

trabalho infantil, migração familiar, probit bivariado, decomposição de Oaxaca

Classificação JEL J22, O15, O54

\footnotetext{
Key words

child labor, family migration, bivariate probit,

Oaxaca decomposition
}

JEL classification $J 22,015$, 054

\section{Resumo}

Este trabalho analisa o impacto da condição de migração dos pais sobre a probabilidade de trabalhar/estudar dos filhos entre $10 \mathrm{e}$ 14 anos no estado de São Paulo. Com base em uma tipologia familiar estabelecida de acordo com as combinaçóes da condição de migração de pais e mães, estimamos um probit bivariado para meninos e meninas. As diferenças das probabilidades encontradas e decompostas através do método de Oaxaca mostram que os filhos de casais migrantes recentes possuem maior probabilidade de trabalhar, graças à desvantagem de seus pais no mercado de trabalho. No caso das crianças de famílias monoparentais, os filhos de mães migrantes têm maiores chances de trabalhar que os filhos de mães não migrantes.

\section{Abstract}

This work analyzes the impact of the migration of parents on the probability that children between 10 to 14 years of age in São Paulo state are working or studying. On the basis of a family category established in accordance with the combinations of mother's and father's migration conditions, we estimate a bivariate probit for boys and girls. The differences between the probabilities found and decomposed by the Oaxaca method show that the children of recent migrant couples are more likely to work, due to the disadvantage of their parents in the job market. In the case of children of single parent families, children of migrant mothers are more likely to work than children of non-migrant mothers. 


\section{1_Introdução}

O objetivo deste artigo é verificar se as crianças de pais migrantes vis-à-vis aquelas de pais não migrantes melhoram as suas condiçóes de vida expressas pela escolha escola/trabalho. O estudo é desenvolvido principalmente por meio da análise das características dos pais, considerando o seguinte dilema: o retorno do investimento realizado pelos pais no momento da mudança geográfica e a progressiva melhora na situação socioeconômica no local de destino são transferidos aos filhos menores, aumentando-lhes a probabilidade de estudar, poupando-os assim da inserção precoce no mercado de trabalho? Ou o peso do custo de adaptação da família ao novo ambiente, que se explicita particularmente pelo fato de os pais desconhecerem os mecanismos de funcionamento do mercado de trabalho, interfere na trajetória estudo/trabalho da criança aumentando a sua probabilidade de trabalhar e diminuindo a de estudar?

A inserção precoce do indivíduo em atividades econômicas em detrimento da efetivação de investimentos em educação prejudica a sua possibilidade de ascensão social e traz impactos negativos na distribuição de renda intergeracional. Por esse motivo, a questão do trabalho infantil está intrinsecamente relacionada à pobreza, sendo simultaneamente causa e consequência desta última. O problema da armadilha do trabalho infantil, que perpetua a situação de pobreza ao longo das gerações, advém do fato de o tempo gasto com o trabalho diminuir as possibilidades de a criança estudar, ou ainda debilitar o seu aproveitamento das atividades escolares.

Economicamente, o processo migratório também é um mecanismo de reversão da condição social das populaçôes de regióes pobres. Em geral, o indivíduo migrante se desloca na expectativa de alcançar melhores condições de vida, um nível mais elevado de bem-estar para si e para a sua família. O movimento migratório é um dos meios pelo qual o indivíduo procura desvencilhar-se de escolhas que, na verdade, não foram suas: $\mathrm{o}$ local e a família em que nasceu. Caso parte dos atributos transmitidos pela sua família não seja adequada e/ou o local de sua residência não apresente alternativas para a sua ascensão socioeconômica, pode-se tentar reverter essa situação procurando outra localidade onde as suas habilidades possam ser mais valorizadas. ${ }^{1}$ Essa é uma decisão pessoal.

Do ponto de vista da criança, nem o seu local de residência nem a sua oferta de trabalho são decisóes pessoais. Assim, a análise deve recair sobre as ca-
${ }^{1}$ A falta de alternativas para melhorar a situação de bem-estar no local de origem pode estar relacionada à ausência de acesso irrestrito à educação, ou ao fato de a sociedade atribuir pouco valor às habilidades intrínsecas do indivíduo. 
racterísticas dos pais e sobre as diferenças entre as regiôes de origem e de destino. Desse modo, o primeiro recorte a ser realizado para a análise dos efeitos da migração sobre a alocação do tempo dos filhos de migrantes entre a escola e o trabalho diz respeito à diferenciação da decisão de migrar pessoal vis-à-vis à decisão familiar. Essa distinção faz-se importante, pois os determinantes da migração familiar são diferentes daqueles da migração individual.

Apesar de a amostra deste trabalho estar circunscrita a crianças entre 10 e 14 anos no estado de São Paulo, acreditamos que a relevância desta Unidade da Federação quanto à capacidade de atração da maior parte do fluxo de migração interna brasileira permite uma análise mais focalizada dos resultados obtidos.

O presente trabalho se encontra estruturado em quatro seções, além desta introdução e das considerações finais. $\mathrm{Na}$ primeira, apresentamos as relaçóes entre a migração e a oferta de trabalho infantil, enfatizando a importância da renda familiar. A seguir, apontamos os determinantes de migração familiar e a sua interferência na decisão dos pais quanto à alocação do tempo de seus filhos entre a escola e o trabalho. Na seção 3, explicamos o conceito de migrante empregado neste trabalho e os procedimentos me- todológicos aplicados. Na quarta seção, apresentamos a análise detalhada do trabalho infantil no estado de São Paulo por meio da aplicação de um modelo probit bivariado, de acordo com a condição de migração dos pais.

\section{2_ Trabalho infantil, renda e migração familiar}

Várias razões podem levar à inserção precoce da criança no mercado de trabalho, mas o principal motivo apontado pela maioria dos estudos econômicos se refere à baixa renda familiar. Assim, a oferta da mão de obra das crianças é explicada como consequência da queda do consumo abaixo de um nível mínimo desejado pela família, que pode ocorrer em maior ou menor grau dependendo do período do ciclo familiar.

O modelo teórico altruísta de Basu e Van (1998) formaliza a questão do trabalho infantil por meio de dois axiomas básicos - bem de luxo (luxury) e bem de substituição (substitution). O primeiro axioma trata da decisão familiar de ofertar o trabalho dos filhos. De acordo com os autores, a inserção das crianças no mercado de trabalho ocorre a partir do momento em que a renda dos adultos cai abaixo de um determinado nível de subsistência definido pela própria família. Nesses ca- 
sos, o tempo da criança destinado ao lazer e/ou à escola passa a ser um bem de luxo para a unidade familiar. O segundo axioma, da substituição de bens, indica que as firmas substituem o trabalho adulto pelo infantil de acordo com determinado fator de equivalência. ${ }^{2}$ Dessa maneira, partindo de uma proposição para a oferta e outra para a demanda, o modelo proposto por Basu e Van conclui que o mercado de trabalho tem equilíbrios múltiplos, nos quais a criança trabalha quando seus pais recebem baixos salários, e é poupada quando os adultos da família têm uma remuneração elevada.

Esses dois equilíbrios são resultados lógicos advindos das duas proposições apontadas anteriormente; entretanto, nos estudos econômicos, a constatação empírica do grau de possibilidade da substituição do trabalho de adultos pelo de crianças é praticamente inexistente. ${ }^{3}$ Por outro lado, a proposição referente à oferta da mão de obra das crianças, além de bastante plausível, é amplamente adotada na literatura especializada, abordando questóes que vão desde o nível de renda corrente da família e a incerteza desse fluxo até o acesso a crédito.

Antes mesmo da formalização do modelo de oferta da mão de obra das crianças realizado por Basu e Van (1998), a revisão da literatura sobre os determi- nantes do trabalho infantil realizada por Grootaert e Kanbur (1995) apontou a influência do risco de gerenciamento da renda familiar sobre a decisão de alocação do tempo da criança. Constatou-se que não é apenas a renda familiar corrente que interfere no envio dos filhos para o mercado de trabalho, mas também a percepção de risco a que está exposta a família devido à volatilidade dos rendimentos. Nesse contexto de incerteza, o trabalho infantil faz parte da estratégia de minimizar o risco de interrupção da renda e, portanto, de diminuir o impacto potencial da perda de emprego dos adultos.

Mais recentemente, o estudo teórico de Baland e Robinson (2000) analisou o impacto do acesso ao mercado de crédito na incidência do trabalho infantil. Os autores demonstram que, na presença de restrição ao mercado de crédito, as famílias escolhem intensificar o grau do trabalho das crianças e acabam priorizando o nível de bem-estar presente em detrimento do futuro.

Dessa maneira, percebe-se que o foco central da literatura especializada é o problema da renda familiar e, em última instância, o ambiente de pobreza no qual a criança vive. No entanto, o nível de renda de que a família dispóe, na maioria das vezes, funciona como uma variável-síntese de diversas outras característi-

\footnotetext{
${ }^{2}$ Os autores partem da hipótese de que para a produção existe um grau de equivalência de substitutibilidade entre adultos e crianças $(0<\gamma<1)$.

${ }^{3}$ A lacuna de estudos que relacionam tecnologia e produtividade com trabalho infantil é apontada no texto de Basu e Tzannatos (2003).
} 
${ }^{4} \mathrm{O}$ autor utiliza a mobilidade ocupacional como proxy da mobilidade social e, empregando uma matriz de transição de status, compara a ocupação do pai com a do filho. cas econômico-demográficas, observáveis ou não, como nível de instrução dos pais, cor da pele, ocupação, tamanho e estrutura familiar, etc. Por esse motivo, paralelamente à questão estritamente monetária, a estrutura familiar e as características dos pais são relevantes, uma vez que determinam a renda familiar e consequentemente interferem na decisão sobre a oferta da mão de obra dos filhos.

Do mesmo modo que o nível educacional, a condição de migração dos pais também se relaciona com a questão do trabalho infantil por meio da determinação de seus rendimentos. No Brasil, devido à heterogeneidade do desenvolvimento regional, o deslocamento geográfico é utilizado pelos indivíduos como um mecanismo capaz de aumentar a possibilidade de ascensão econômica. Ao analisar a mobilidade social no Brasil com dados da PNAD (Pesquisa Nacional por Amostra de Domicílios) de 1973, o trabalho de Pastore (1979) mostra que a mobilidade total dos migrantes é cerca de 30\% maior com relação à dos não migrantes. Do total da mobilidade, a maior participação cabe ao componente estrutural nos dois grupos, embora seja mais importante entre os migrantes. ${ }^{4}$

O estudo de Martine (1980), por outro lado, afirma que essa aparente mobilidade dos migrantes seria, na verda- de, o resultado líquido de dois processos distintos e de certa forma antagônicos: a adaptação progressiva dos mais aptos a competir no mercado de trabalho local, e a evasão sistemática dos menos capacitados em direção a outras localidades. Os dois estudos, embora não concordem quanto ao grau de abrangência da hipótese de adaptação progressiva dos migrantes, afirmam que os migrantes apresentam maior mobilidade ascendente ou descendente que os não migrantes.

Nesse sentido, por meio dos processos de seletividade e adaptaçáo, os migrantes constituem uma população que se diferencia da não migrante. Por esse motivo, além das variáveis correntes na determinação da renda, os migrantes possuem outras características que não são diretamente mensuráveis, mas contribuem para a percepção mais elevada de seu rendimento, especialmente quando as características observáveis são controladas pela variável educação. Assim, em conformidade com a literatura especializada que corrobora a seletividade positiva dos migrantes, cabe desenvolver as relaçóes entre o mecanismo da migração e a determinação da oferta de trabalho infantil.

$\mathrm{O}$ efeito do tempo de residência sobre a experiência migratória se dá tanto no nível individual, quanto no familiar. Ao mesmo tempo que o ciclo de vida fa- 
miliar cria externalidades distintas sobre os membros da família migrante, ${ }^{5}$ o processo migratório também traz impactos sobre estes, interferindo nas decisões de procriação e de oferta de trabalho de seus membros. Dessa maneira, a migração abre espaço para estabelecer diversos tipos de arranjo doméstico de alocação de tempo dos seus membros, inclusive das crianças. Além disso, a dificuldade ou não da inserção dos pais no mercado de trabalho do local de destino traz elementos adicionais para a decisão de ofertar a mão de obra dos filhos.

\section{3_Migração dos pais, impacto na trajetória do ciclo de vida das crianças}

Do ponto de vista econômico, o esforço despendido no processo migratório é realizado devido à expectativa de que o padrão de vida no local de destino será melhor do que aquele vivenciado no local de origem. A literatura econômica brasileira referente à migração se concentra principalmente na análise do diferencial de renda de indivíduos adultos migrantes em relação aos não migrantes. De maneira geral, os estudos confirmam a autosseleção dos migrantes pela verificação de que, em média, estes ganham mais que os não migrantes mesmo após o controle de suas variáveis. Essa diferença é provocada por características não observáveis, que geralmente são associadas com maior aptidão, menor aversão ao risco entre outras (SANTOS JUNIOR, 2002; SILVEIRA NETO e MAGALHÂES, 2004).

Devido à comprovação da seletividade positiva dos migrantes, uma segunda conclusão corrente na literatura é que o deslocamento geográfico recompensa positivamente os indivíduos, particularmente quanto à obtenção de uma renda maior e de uma melhor ocupação. Mas essa abordagem geralmente trata os migrantes como pessoas únicas, sem relação com qualquer outro indivíduo no local de origem. As decisóes de migrar, de se inserir no local de destino ou ainda de retornar são baseadas no próprio ganho individual, subentendendo-se que os migrantes não levam em conta o bemestar de dependentes e/ou parentes. Desse modo, não se distingue o migrante individual daquele que tomou essa decisão no âmbito familiar. Os estudos, portanto, não focam o impacto da migração sobre o bem-estar dos cônjuges e filhos.

O tema do contexto familiar na literatura econômica referente aos determinantes da migração começou a ser tratado em meados da década de 1970, com os trabalhos de Sandell (1975), Da Vanzo (1976) e Mincer (1978), que foca-
${ }^{5}$ Por exemplo, o fato de os pais migrarem com ou sem o filho, a idade das crianças no momento do deslocamento da família ou o tempo de permanência dos adultos no local de destino no período de nascimento do filho criam externalidades distintas sobre os membros da família, tendo influência sobre o seu nível de renda e sobre a incidência de trabalho infantil. 
${ }^{6}$ A situação e a posição do cônjuge no mercado de trabalho do local e de origem, o tamanho da família, a existência e a idade das crianças, etc.

${ }^{7}$ No caso de a criança estar ociosa, essa possibilidade torna-se ainda mais atrativa. lizam a migração interna nos Estados Unidos. Esses estudos abordam a decisão de migrar da família, considerando casais de indivíduos adultos sem, no entanto, estender o modelo para incluir explicitamente os filhos.

A principal diferença nos fatores determinantes da migração individual e da migração familiar é que, no caso familiar, a migração impóe a necessidade de os membros negociarem perdas e ganhos intrafamiliarmente. Assim, devido ao custo implícito ao processo de barganha, tem-se que o retorno da migração familiar tende a aumentar menos proporcionalmente que os respectivos custos, os quais são variados e dependem da avaliação de muitos outros fatores. ${ }^{6}$ Por isso, a literatura migratória é unânime em afirmar que a família é um obstáculo ao deslocamento.

Quando se passa a considerar a e xistência de filhos, a computação dos custos e dos benefícios devido à migração se torna mais complexa. É possível afirmar que a migração familiar introduz a questão intertemporal na trajetória do ciclo de vida da criança, referente a uma decisão que foi realizada pelos pais. Para se entender melhor os efeitos da migração dos pais sobre a probabilidade de a criança trabalhar, é preciso separar os impactos de curto prazo e de longo prazo, a depender de há quanto tempo os pais migrantes se encontram no local de destino.

No curto prazo, os pais se adaptam ao mercado de trabalho, enquanto a criança se insere e se acostuma à vida escolar. Caso os pais não consigam se inserir no mercado de trabalho local ou caso essa inclusão ocorra de maneira precária o que implica baixo rendimento -, o uso da mão de obra dos filhos passa a ser uma alternativa para a expansão da renda familiar. ${ }^{7}$ Por outro lado, no longo prazo, em virtude da seletividade positiva dos migrantes, os filhos dos pais que residem na regiáo atual há mais tempo podem, inclusive, ter uma probabilidade de trabalhar inferior à dos filhos de não migrantes. Paralelamente à questão do trabalho infantil, dependendo do local de origem e de destino da família, o deslocamento também pode permitir que a criança tenha acesso maior à escola, e/ou a escolas de melhor qualidade. Ou seja, a migraçáo bem-sucedida pode contribuir para o rompimento da transmissão intergeracional da pobreza.

Devido a um conjunto de variáveis e situaçóes que diferenciam a família migrante da não migrante, imagina-se que as probabilidades de trabalho infantil de seus filhos também sejam distintas, principalmente se distinguirmos o processo migratório entre prazos mais cutos ou mais longos. 


\section{4_Conceito de migrante, aspectos da amostra $e$ procedimentos metodológicos}

Os estudos econômicos no Brasil que analisam as diferenças de renda entre migrantes e não migrantes abordam em geral os deslocamentos interestaduais, portanto empregam o conceito de migrante para o indivíduo que nasceu em uma Unidade da Federação (UF) distinta daquela em que reside. Essa definição não leva em consideração há quanto tempo o migrante reside no local de destino, fazendo com que no mesmo grupo estejam compreendidos tanto indivíduos recém-chegados menos de três anos de residência no local de destino - quanto aqueles que moram em um determinado estado da federaçáo há mais de 5, 10, 15 ou 20 anos.

$\mathrm{O}$ fato de este artigo focalizar o trabalho infantil na faixa etária de 10 a 14 anos faz com que, segundo nossas análises, o grupo de migrantes antigos transfira custos de deslocamento menores aos seus filhos que o grupo de migrantes recentes. Os filhos de pais não migrantes constituirão a base de comparação de nossa análise, uma vez que não arcaram com custos de adaptaçáo nem têm responsáveis positivamente selecionados. Assim, a decisão escola/trabalho das crianças cujos pais migraram será realizada vis-à-vis à mesma escolha dos filhos de pais não migrantes. ${ }^{8} \mathrm{Ou}$ seja, verificaremos o impacto da migração sobre a criança em termos da frequência escolar e da oferta de trabalho.

A análise não está restrita somente aos migrantes que nasceram em outro estado, mas também aos indivíduos que, sendo paulistas, residiram em outra Unidade da Federação e retornaram ao estado de São Paulo, requerendo também um custo de adaptação. Para separar os impactos de curto e de longo prazo do deslocamento dos pais, construímos quatro categorias de migrantes, de acordo com o tempo de residência no local de destino.

No caso das crianças entre 10 e 14 anos, qualquer migração que aconteceu há pelo menos 10 anos incorpora, no máximo, a ocorrência de filhos que chegaram ao estado de São Paulo com faixa etária inferior à fase de alfabetização. ${ }^{9}$ Mesmo assim, analisamos essa categoria de migrantes pelos possíveis impactos de longo prazo quando os pais migrantes vindos de outra UF já passaram pelo processo de adaptação e continuam no estado de São Paulo.

Ao introduzir a questão temporal na avaliação do impacto do processo migratório dos pais sobre os filhos, abrese espaço para verificar se o problema de adaptação dos adultos ao mercado de trabalho local é capaz de interferir no bem-

\footnotetext{
${ }^{8}$ Os dados do Censo Demográfico não permitem constatar se as crianças pertencentes a famílias migrantes frequentavam a escola no local de origem. Dessa maneira, não se pode averiguar se a criança está em uma situação melhor quanto à sua inserção escolar após o deslocamento migratório.

${ }^{9}$ A idade mínima para a matrícula no Ensino

Fundamental é sete anos.
} 
Quadro 1_Categorias de migrantes utilizadas

\begin{tabular}{c|c|c|c}
$\begin{array}{c}\text { Categoria } \\
\text { migrante }\end{array}$ & $\begin{array}{c}\text { Unidade da Federação } \\
\text { Nascimento }\end{array}$ & $\begin{array}{c}\text { Tempo residência } \\
\text { Destino }\end{array}$ & no estado de São Paulo \\
\hline Curto Prazo $(\mathrm{CP})$ & Fora de São Paulo & São Paulo & Há menos de 10 anos \\
\hline Longo Prazo (LP) & Fora de São Paulo & São Paulo & Há pelo menos 10 anos \\
\hline Retornado & Sáo Paulo & São Paulo & Há menos de 10 anos \\
\hline Náo Migrante & Sáo Paulo & $\ldots \ldots \ldots$ & $\ldots \ldots \ldots$
\end{tabular}

Fonte: Elaboração própria.

estar das crianças. A apresentação da taxa de trabalho infantil e de frequência escolar das crianças de acordo com a condição de migração do seu responsável (Tabela 1) mostra que existem diferenças que não podem ser captadas ao se aplicar o concei- to de migrante sem distinçấo de tempo de residência e de origem.

Conforme pode ser observado, a classificação da condição de migração do responsável pela família permite visualizar que existe uma distinção entre

Tabela 1_Trabalho infantil e frequência escolar de acordo com a condição de migração do responsável pela família - em \%

\begin{tabular}{l|c|c|c|c}
\multicolumn{1}{c|}{$\begin{array}{c}\text { Condição de migração } \\
\text { do responsável pela família }\end{array}$} & $\begin{array}{c}\text { Trabalho } \\
\text { Infantil }\end{array}$ & $\begin{array}{c}\text { Frequência } \\
\text { Escolar }\end{array}$ & $\begin{array}{c}\text { Mrabalho } \\
\text { Infantil }\end{array}$ & $\begin{array}{c}\text { Frequênci } \\
\text { Escolar }\end{array}$ \\
\hline Não migrante & 2,84 & 97,57 & 1,95 & 97,91 \\
\hline Migrante de curto prazo & 3,41 & 95,35 & 2,29 & 95,58 \\
\hline Paulista Retornado & 2,88 & 96,84 & 2,37 & 97,82 \\
\hline Migrante de longo prazo & 2,90 & 96,99 & 1,86 & 97,35 \\
\hline Total & $\mathbf{2 , 8 9}$ & $\mathbf{9 7 , 2 2}$ & $\mathbf{1 , 9 5}$ & $\mathbf{9 7 , 5 7}$ \\
\hline Paulista & 2,84 & 97,56 & 1,96 & 97,91 \\
\hline Não Paulista & 2,98 & 96,72 & 1,93 & 97,06
\end{tabular}

Fonte: Censo Demográfico, elaboração própria. 
os próprios filhos de migrantes vindos de outro estado, como também entre os paulistas não migrantes e os retornados, particularmente no caso das meninas. Além disso, constata-se que a diferença da frequência escolar entre os filhos de migrantes - independente da categoria - e os filhos de não migrantes é maior que a discrepância verificada em relação à inserção no mercado de trabalho. ${ }^{10}$

Paralelamente ao potencial de vulnerabilidade dos filhos de migrantes de curto prazo, evidenciamos que a incidência de trabalho infantil para os meninos cujo responsável reside no estado de São Paulo há pelo menos 10 anos é próxima da dos filhos de paulistas não migrantes, e é menor no caso das meninas. Esse fato reforça a hipótese de que a melhor condição socioeconômica dos migrantes após o período de adaptação faz com que seus filhos estejam menos expostos à necessidade de ofertar trabalho. No entanto, essa seletividade positiva dos responsáveis migrantes de longo prazo não se mostra suficiente para compatibilizar a inserção escolar de seus filhos com a dos filhos de não migrantes.

Com os filhos dos migrantes recentes, a situação é mais exacerbada, pois esse grupo se encontra sistematicamente em condição inferior aos demais, particularmente em relação aos filhos de não migrantes. Os dados iniciais indicam que existe algum tipo de diferenciação entre os grupos, não sendo possível afirmar se ela advém de fatores observáveis, por exemplo, a baixa renda familiar, ou de fatores não observáveis, como o processo de adaptação e seleção dos migrantes. Contudo, as duas evidências apresentadas acima são indícios da existência de mecanismos intergeracionais da pobreza entre os migrantes.

Para distinguir se a diferença da alocação do tempo entre escola/trabalho das crianças deve-se a fatores observáveis ou ao processo migratório é preciso analisar as características dos pais. No estudo de Ferreira-Batista (2006) encontra-se a decomposição da discrepância dos rendimentos desta subamostra de pais (pai e mãe) migrantes em relação aos não migrantes com filhos entre 10 e 14 anos que residem na área urbana do estado de Sáo Paulo. ${ }^{11}$ Os resultados encontrados pela autora mostram que, após a aplicação do controle das variáveis observáveis, os pais migrantes de curto prazo e os retornados

$\begin{array}{ll}{ }^{10} \text { As filhas de paulistas } & \text { estimadas oito equaçóes de } \\ \text { retornados sáo exceçáo. } & \text { rendimento (quatro para os pais } \\ { }^{11} \text { A autora aplicou o método } & \text { e quatro para as mães) por meio } \\ \text { de Oaxaca para a equação de } & \begin{array}{l}\text { do procedimento de Heckman } \\ \text { rendimentos minceriana de }\end{array} \\ \text { pais e mães. No total, foram } & \begin{array}{l}\text { para correçáo do problema de } \\ \text { seletividade amostral. }\end{array}\end{array}$


estão em situação de desvantagem com relação aos não migrantes. Em contrapartida, as mães dessas duas mesmas categorias de migrantes estão em posição vantajosa. Quanto aos migrantes de longo prazo, tanto pais quanto mães são positivamente selecionados.

No que diz respeito às crianças, os microdados do Censo Demográfico apontam a existência de 287.812 crianças de $10 \mathrm{a} 14$ anos que residem na área urbana do estado de São Paulo e ocupam a posição familiar de filho. ${ }^{12} \mathrm{~A}$ distribuição entre meninos e meninas é praticamente equivalente - 50,9\% e $49,1 \%$, respectivamente. A maioria das famílias com filhos entre 10 e 14 anos que residem no estado de São Paulo é constituída de pai e mãe. O responsável pela família não possui cônjuge em apenas $17,5 \%$ das famílias. Na maioria das famílias monoparentais, a mulher é
${ }^{12}$ Esse total refere-se aos dados não ponderados da amostra e não inclui as crianças que residem na área urbana e que executam atividades agrícolas, de silvicultura ou de pesca.

\footnotetext{
${ }^{13}$ No total, $15,8 \%$ das crianças compóem famílias monoparentais cuja pessoa responsável é a mãe. A parcela de aproximadamente $1,7 \%$ de filhos entre 10 e 14 anos que se encontrava em famílias monoparentais chefiadas por pais foi excluída do estudo.
}

a responsável pelo sustento e administração do lar $(91,5 \%){ }^{13}$

A constatação de que a migração ocorre num contexto familiar pode ser confirmada na Tabela 2, que traz o tempo de residência de pais e máes que são migrantes de curto prazo.

Apesar de não ser possível investigar se ao longo de todo o tempo de residência no estado as unióes entre os migrantes foram estáveis, pressupomos que o fato de mais de $80 \%$ dos casais com filhos de 10 a 14 anos chegarem ao estado no mesmo ano é um forte indicativo de que a migração é de ordem familiar.

No entanto, apesar da maior parte da migração ser de ordem familiar, nem sempre o casal se encontra na mesma ca-

\section{Tabela 2_Combinação do tempo de chegada dos responsáveis e cônjuge no estado de São Paulo - em \%}

\begin{tabular}{|c|c|c|}
\hline \multirow{2}{*}{ Cônjuge } & \multicolumn{2}{|c|}{ Responsável } \\
\hline & Pai & Mãe \\
\hline Chegou antes & 3,9 & 10,1 \\
\hline-1 ano antes & 1,7 & 4,1 \\
\hline-2 ou mais anos antes & 2,1 & 6,0 \\
\hline Chegou no mesmo ano & 82,7 & 81,4 \\
\hline Chegou depois & 13,4 & 8,5 \\
\hline-1 ano depois & 7,1 & 2,6 \\
\hline-2 ou mais anos depois & 6,4 & 5,9 \\
\hline
\end{tabular}

Fonte: Censo Demográfico, elaboraçăo própria. 
Tabela 3 - Combinação da condição de migração de pai e mãe (em \%)

\begin{tabular}{|c|c|c|c|c|c|}
\hline Pai & $\ldots \ldots \ldots$ & migrante CP & $\begin{array}{l}\text { Mãe } \\
\text { retornado }\end{array}$ & migrante LP & Amostra \\
\hline não migrante & 80,6 & 6,9 & 16,2 & 32,0 & 142.870 \\
\hline migrante CP & 0,9 & 73,9 & 24,9 & 1,9 & 16.099 \\
\hline retornado & 0,3 & 4,8 & 53,2 & 0,2 & 2.974 \\
\hline migrante LP & 18,2 & 14,5 & 5,7 & 65,9 & 80.233 \\
\hline Amostra & 144.231 & 17.047 & 2.938 & 77.960 & 242.176 \\
\hline
\end{tabular}

Fonte: Censo Demográfico, elaboração própria.

tegoria de migrante. ${ }^{14}$ Essa distinção é relevante, pois as diversas possibilidades de combinação da condição de migração do pai e da mãe interferem no impacto da adaptação familiar no local de destino em termos de acesso a informaçóes importantes sobre o mercado de trabalho local e/ou o sistema escolar. Por esse motivo, a amostra foi desagregada de acordo com as diferentes possibilidades de combinação da condição de migração de pai e mãe, como mostra a Tabela 3.

Os dados indicam que $75 \%$ dos casais com crianças entre 10 e 14 anos têm a mesma condição de migração, sendo que essa similaridade ocorre com maior frequência entre os não migrantes e os migrantes de curto prazo. O grupo que apresenta maior dispersão é o das paulistas retornadas que, apesar de apresentar um pouco mais da metade dos cônjuges na mesma condição de migração, mostra cerca de um quarto do grupo casado com pais migrantes de curto prazo, e 16,2\% casados com pais paulistas não migrantes. ${ }^{15}$

Além das famílias constituídas por um casal, consideramos as crianças que são criadas em lares monoparentais, que somam 45.636. Neste caso, não existe a problemática da distinção da situação de adaptação ou não de um dos cônjuges, pois se a pessoa de referência da família for migrante de curto prazo ou retornada, abre-se a oportunidade de a criança arcar com o custo de adaptaçáo ao local da nova residência. ${ }^{16}$

$\begin{array}{ll}{ }^{14} \text { Existe um conjunto de } & \text { limitada, pois ele representa } \\ \text { situaçóes: pai migrante } & \text { apenas } 1,3 \% \text { da amostra } \\ \text { de curto prazo casado com } & \text { total das famílias. } \\ \text { mãe paulista retornada, ou } & { }^{16} \text { A situaçáo da falta de } \\ \text { mãe paulista não migrante } & \text { cônjuge também abre a } \\ \text { cujo cônjuge é migrante de } & \text { possibilidade de que tenha } \\ \text { longo prazo, etc. } & \text { ocorrido a separação do } \\ { }^{15} \text { No entanto, a importância } & \text { casal depois de a família } \\ \text { desse grupo de retornados é } & \text { ter migrado. }\end{array}$


Diante da maior ocorrência, estabelecemos a amostra deste estudo distinguindo as crianças de dois tipos de famílias: casal com a mesma condição de migração e família monoparental sob a responsabilidade da mãe. Essa classificação será utilizada na separação das crianças para estimar a probabilidade de estudar/trabalhar com o objetivo de precisar os efeitos que o deslocamento dos pais acarreta sobre o bem-estar de seus filhos no curto e no longo prazo.

\section{5_Análise da probabilidade de escolha das crianças entre escola e trabalho}

Existem várias maneiras de modelar econometricamente a oferta de trabalho infantil, que depende particularmente das hipóteses sobre a tomada de decisão da família no que concerne à alocação do tempo do menor. ${ }^{17}$ Neste trabalho, esti- mamos a probabilidade de a criança estudar/trabalhar por meio da técnica do probit bivariado.

Essa escolha se deve a sua principal característica de não impor qualquer formato específico para a tomada de decisão - decisão simultânea, sequencial, etc. -, mas de supor que ambas as opçóes estão relacionadas entre si de alguma maneira. A possibilidade de algum tipo de relaçáo entre as decisóes de estudar/trabalhar deriva do fato de este método se constituir de dois probits univariados, estimados conjuntamente, permitindo assim que os resíduos de cada uma das regressóes possam estar correlacionados. ${ }^{18} \mathrm{~A}$ forma do probit bivariado estimado é dada por:

$$
\begin{aligned}
Y_{1 i}^{*} & =\mathrm{X}_{1 i} \beta_{i}+\mu_{1 i} \\
Y_{1 i} & =1 \text { se } Y_{1 i}^{*}>0 \\
Y_{1 i} & =0 \text { caso contrário } \\
Y_{2 i}^{*} & =\mathrm{X}_{2 i} \beta_{i}+\mu_{2 i} \\
Y_{2 i} & =1 \text { se } Y_{2 i}^{*}>0 \\
Y_{2 i} & =0 \text { caso contrário }
\end{aligned}
$$

A primeira variável binária indica se a criança estava matriculada na escola ou não, no momento da aplicação do questionário do Censo. A segunda infor- 
ma se a criança estava trabalhando - remuneradamente ou não remuneradamente - na semana da entrevista. A análise empírica permite que a escolha simultânea destas duas opçóes implique quatro resultados diferentes e excludentes entre si: só estuda $\left(Y_{1 i}=1 e Y_{2 i}=0\right)$, estuda e trabalha $\left(Y_{1 i}=1 e Y_{2 i}=1\right)$, só trabalha $\left(Y_{1 i}=0 e Y_{2 i}=1\right)$ ou nenhum dos dois ( $\left.Y_{1 i}=0 e Y_{2 i}=0\right) \cdot{ }^{19}$

Se as duas decisões são correlacionadas, temos que os erros dos dois modelos não são independentes entre si $\left(\rho=\operatorname{Cov}\left(\mu_{1 i}, \mu_{2 i}\right) \neq 0\right)$ a probabilidade de uma opção depende da probabilidade da outra, sendo determinadas conjuntamente. Por outro lado, caso $\rho=0$, as escolhas entre estudar e trabalhar não têm relação entre si e os probits não precisam ser estimados conjuntamente.

Além dos coeficientes $\beta_{1}$ e $\beta_{2}$, o probit bivariado fornece também a estimação da probabilidade prevista das quatro combinaçóes possíveis apontadas anteriormente. Com base nessas estimativas obtidas separadamente para os dois tipos de família, calculamos o diferencial da probabilidade de trabalhar e de estudar dos filhos de migrantes e de não migrantes. Esse procedimento fez uso de uma modificação do método de decomposição de Oaxaca aplicado à estimativa do probit bivariado. ${ }^{20}$

A diferença entre as probabilidades de estudar/trabalhar dos filhos de migrantes e de não migrantes é obtida diretamente de $\left(E_{m \succ 1}^{*}-E_{m=1}^{*}\right)$, no caso da frequência escolar, e de $\left(T_{m \succ 1}^{*}-T_{m=1}^{*}\right)$ para a oferta de trabalho para cada categoria de migrante em relação a não migrantes. ${ }^{21}$

Para decompormos o diferencial das probabilidades previstas de estudar/ trabalhar é preciso distinguir a parcela $\mathrm{da}$ variação que ocorre devido às alteraçóes das características observadas - variáveis explicativas - daquela verificada graças a mudanças no vetor dos parâmetros estimados - parcela não explicada. Sendo assim, o diferencial das probabilidades de estudar/trabalhar dos filhos de pais migrantes e não migrantes será calculado da seguinte maneira:

\footnotetext{
${ }^{19}$ A função de verossimilhança do probit bivariado estimado e a densidade conjunta dos erros

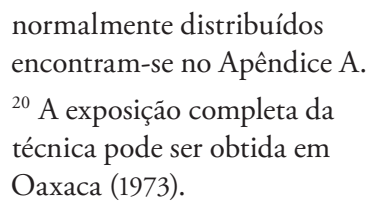

${ }^{21} \mathrm{O}$ índice $m$ diz respeito à condição de migração dos pais, onde $m=1$ se refere aos não migrantes, e o $m>1$ indica as

três categorias de migrante: curto prazo $(m=2)$, retornado $(m=3)$ ou longo prazo $(m=4)$.
} 


$$
\begin{aligned}
& E_{m \succ 1}^{*}-E_{m=1}^{*}= \sum_{j=0}^{1}\left[\operatorname{Pr}\left(Y_{1}=1, Y_{2}=j / X_{m \succ 1}, \theta_{m \succ 1}^{*}\right)-\operatorname{Pr}\left(Y_{1}=1, Y_{2}=j / X_{m=1}, \theta_{m \succ 1}^{*}\right)\right]+ \\
& \sum_{j=0}^{1}\left[\operatorname{Pr}\left(Y_{1}=1, Y_{2}=j / X_{m=1}, \theta_{m \succ 1}^{*}\right)-\operatorname{Pr}\left(Y_{1}=1, Y_{2}=j / X_{m=1}, \theta_{m=1}^{*}\right)\right] \\
& T_{m \succ 1}^{*}-T_{m=1}^{*}=\sum_{j=0}^{1}\left[\operatorname{Pr}\left(Y_{2}=1, Y_{1}=j / X_{m \succ 1}, \theta_{m \succ 1}^{*}\right)-\operatorname{Pr}\left(Y_{2}=1, Y_{1}=j / X_{m=1}, \theta_{m \succ 1}^{*}\right)\right]+ \\
& \sum_{j=0}^{1}\left[\operatorname{Pr}\left(Y_{2}=1, Y_{1}=j / X_{m=1}, \theta_{m \succ 1}^{*}\right)-\operatorname{Pr}\left(Y_{2}=1, Y_{1}=j / X_{m=1}, \theta_{m=1}^{*}\right)\right]
\end{aligned}
$$

onde temos: $j=0,1$ e $2 \leq m \leq 4$

Diferencial $=$ variação explicada + variação não explicada

Nas equaçóes (2.1) e (2.2), a primeira somatória corresponde à parcela da variação que pode ser explicada, e a segunda diz respeito à porção da variação total que não pode ser explicada. ${ }^{22}$ Percebe-se que na parcela explicável, os parâmetros estimados para a amostra de filhos de migrantes $\left(\theta_{m \succ 1}^{*}\right)$ ficam constantes, enquanto as características observadas são alternadas entre migrantes e não migrantes $\left(X_{m \succ 1}, X_{m=1}\right)$. Isso significa que o primeiro somatório refere-se à diferença entre a probabilidade de estudar/trabalhar que se deve única e exclusivamente à discrepância entre as características de filhos de migrantes e de não migrantes. ${ }^{23}$

O segundo termo do somatório nas equaçôes (2.1) e (2.2), por outro lado, mantém as características observáveis de filhos de não migrantes constantes $\left(X_{m=1}\right)$, mas permite que os parâmetros estimados $\left(\theta_{m \succ 1}^{*}, \theta_{m=1}^{*}\right)$ variem. Dessa maneira, procuramos constatar em que dimensão o peso do efeito de ser filho de pais

\begin{abstract}
${ }^{22}$ Esta decomposição do diferencial das probabilidades de estudar/trabalhar dos migrantes e dos não migrantes foi obtida pela soma e subtraçáo dos termos $\operatorname{Pr}\left(Y_{1}=1, Y_{2}=j / X_{m=1}, \theta_{m>1}^{*}\right)$ e $\operatorname{Pr}\left(Y_{2}=1, Y_{1}=j / X_{m \succ 1}, \theta_{m \succ 1}^{*}\right)$
\end{abstract}

nas equaçóes (2.1) e (2.2), respectivamente. No entanto, é importante apontar que existe outra maneira de se obter a decomposição do diferencial das probabilidades estimadas, onde os termos a serem somados e subtraídos correspondem a

$$
\begin{aligned}
& \operatorname{Pr}\left(Y_{1}=1, Y_{2}=j / X_{m \succ 1}, \theta_{m=1}^{*}\right) \mathrm{e} \\
& \operatorname{Pr}\left(Y_{2}=1, Y_{1}=j / X_{m \succ 1}, \theta_{m=1}^{*}\right) \text { nas }
\end{aligned}
$$

equaçôes (2.1) e (2.2). Porém, o resultado não deve ser o mesmo porque, na verdade, cada uma das possibilidades está comparando situaçôes distintas.

\author{
${ }^{23}$ Ou seja, realiza-se o \\ seguinte questionamento: \\ "Caso os filhos dos pais \\ migrantes tivessem as mesmas \\ características pessoais, \\ familiares e de localidade que \\ os filhos dos pais não migrantes, \\ qual seria a probabilidade \\ prevista de essas crianças \\ estudarem/trabalharem?".
}


migrantes contribui para a diferença das probabilidades de estudar/trabalhar com relação ao filho de pais não migrantes. Esta segunda parcela é convencionalmente conhecida como componente de discriminação, pois crianças com os mesmos atributos têm probabilidades de estudar/trabalhar distintas devido ao peso atribuído a todas as características de acordo com a condição de migração dos pais. Vale lembrar que essa discriminação se refere tanto à diferença dos coeficientes estimados das variáveis explicati- vas dos dois grupos, quanto à diferença de intercepto.

A distribuição da amostra final do estudo segundo sexo, juntamente com a frequência escolar e a taxa de trabalho infantil para cada tipo de família, são apresentadas na Tabela 4 a seguir. ${ }^{24}$

As variáveis explicativas utilizadas na estimação (Quadro 2, a seguir) foram selecionadas com base na revisão bibliográfica da literatura especializada, particularmente nos estudos mais recentes do caso brasileiro, tais como

\section{Tabela 4 - Distribuição das crianças, frequência escolar e trabalho infantil de acordo com o tipo de família - em \%}

\begin{tabular}{|c|c|c|c|c|c|}
\hline Tipo de arranjo familiar/casal & Total & $\begin{array}{l}\text { Meninos } \\
\text { Estuda }\end{array}$ & Trabalha & $\begin{array}{l}\text { Meninas } \\
\text { Estuda }\end{array}$ & Trabalha \\
\hline Mesma condição de migração & 80,4 & 97,61 & 2,86 & 97,92 & 1,80 \\
\hline - Não migrante* & 51,5 & 97,95 & 2,89 & 98,24 & 1,87 \\
\hline - Migrante curto prazo & 5,6 & 95,74 & 3,13 & 95,91 & 2,24 \\
\hline - Paulista retornado & 0,7 & 97,18 & 3,23 & 98,67 & 1,07 \\
\hline - Migrante longo prazo & 22,5 & 97,30 & 2,71 & 97,66 & 1,58 \\
\hline Mãe sem cônjuge & 19,6 & 95,56 & 3,64 & 96,45 & 2,88 \\
\hline - Não migrante* & 11,7 & 95,93 & 3,55 & 96,89 & 2,78 \\
\hline - Migrante curto prazo & 1,2 & 92,74 & 3,78 & 94,02 & 3,17 \\
\hline - Paulista retornado & 0,3 & 95,61 & 3,80 & 97,32 & 4,76 \\
\hline - Migrante longo prazo & 6,5 & 95,42 & 3,76 & 96,16 & 2,92 \\
\hline Amostra total & 225.378 & 97,29 & 2,98 & 97,62 & 2,00 \\
\hline
\end{tabular}

Obs.: * Categoria que servirá de base de comparação dentro do tipo de família. Fonte: Censo Demográfico, elaboraçẫo própria.

\footnotetext{
${ }^{24}$ Para alcançar a

decomposição do diferencial das probabilidades previstas de estudar/trabalhar das crianças da amostra de acordo com a condição de migração de seus pais, primeiramente estimou-se probit bivariado de meninos e meninas para os dois tipos de famílias (total de 16 equações), obtendose assim as probabilidades previstas estudar/trabalhar para cada probit bivariado. Essas probabilidades previstas foram utilizadas no cálculo do diferencial em parcela explicada e náo explicada após o cálculo de um novo probit bivariado para os filhos dos migrantes (três categorias), utilizando as variáveis explicativas dos filhos dos não migrantes.
} 
Kassouf (1999) e Muniz (2001), entre outros. ${ }^{25}$ No caso da educação dos pais, utilizamos a informação de anos completos de estudo presente no Censo Demográfico, que além de indicar o número de anos completos de estudo entre $0 \mathrm{a}$ 17 anos associa à resposta "não determinado" o valor 20, e à situação "alfabetização de adultos”, o valor 30. Neste estudo, excluíram-se as observaçóes em que o grau de instrução era não determinado, e atribuiu-se quatro anos de estudo para os indivíduos que indicaram ter realizado a alfabetização de adultos. ${ }^{26}$

Já na renda per capita do "não-trabalho" figuram os rendimentos relativos a aposentadoria, aluguel, pensão alimentícia, doação, renda mínima, bolsa-escola e seguro-desemprego. ${ }^{27}$ Parte do tama- nho familiar neste trabalho é computada pela inclusão de duas variáveis que indicam a soma de filhos de 0 a 9 anos e entre 15 a 17 anos. Como a amostra de estudo focaliza os filhos de 10 a 14 anos, esses dois somatórios funcionam como uma proxy da existência (ou não) de irmãos mais novos e/ou mais velhos na família ${ }^{28}$.

Os resultados do probit bivariado para cada tipo de família e as probabilidades previstas correspondentes se encontram nas Tabelas 5.1 e 5.2. Notamos que o rho estimado $(\breve{\rho})$ se mostra significativamente diferente de zero em praticamente todos os probits bivariados, apontando que o componente não explicado da decisão de a criança frequentar a escola está relacionado ao componente não explicado da decisão de ofertar mão de obra. ${ }^{29}$

\footnotetext{
${ }^{25} \mathrm{O}$ Apêndice $\mathrm{B}$ apresenta as estatísticas descritivas para as amostras de meninos $\mathrm{e}$ meninas segundo o tipo de família a que pertencem.

${ }^{26}$ Esta atribuição se deve ao fato de que tanto a alfabetização de adultos quanto o primeiro ciclo do Ensino Fundamental têm como principal objetivo a alfabetização.
}

\author{
${ }^{27}$ Utilizamos a variável rend \\ per capita do "não trabalho", \\ ao invés da renda familiar \\ per capita, para evitar que \\ a especificação do probit \\ bivariado sofra problemas \\ de endogeneidade. Esse \\ tipo de problema deve-se \\ à importância da variável \\ "anos de estudo" para a \\ determinação dos salários, \\ os quais compóem grande \\ parte da renda familiar. Por \\ esse motivo consideramos \\ a variável "anos de estudo"
}

como proxy da renda familiar permanente, contabilizando separadamente apenas a parcela da renda que náo depende da dinâmica de acumulaçáo de capital humano. Esse procedimento também foi utilizado por Kassouf (1999).

\author{
${ }^{28}$ Além de verificar a \\ relevância do tamanho da \\ família sobre a probabilidade \\ de a criança estudar/trabalhar, \\ estas duas variáveis permitem \\ apurar também se ter irmãos \\ mais velhos diminui a \\ probabilidade de a criança \\ trabalhar, enquanto irmãos \\ mais novos ampliam \\ essa possibilidade. \\ ${ }^{29}$ A exceção é o grupo dos \\ filhos de mães retornadas \\ (independentemente \\ do tipo de família).
}




\section{Quadro 2 - Descrição das variáveis utilizadas}

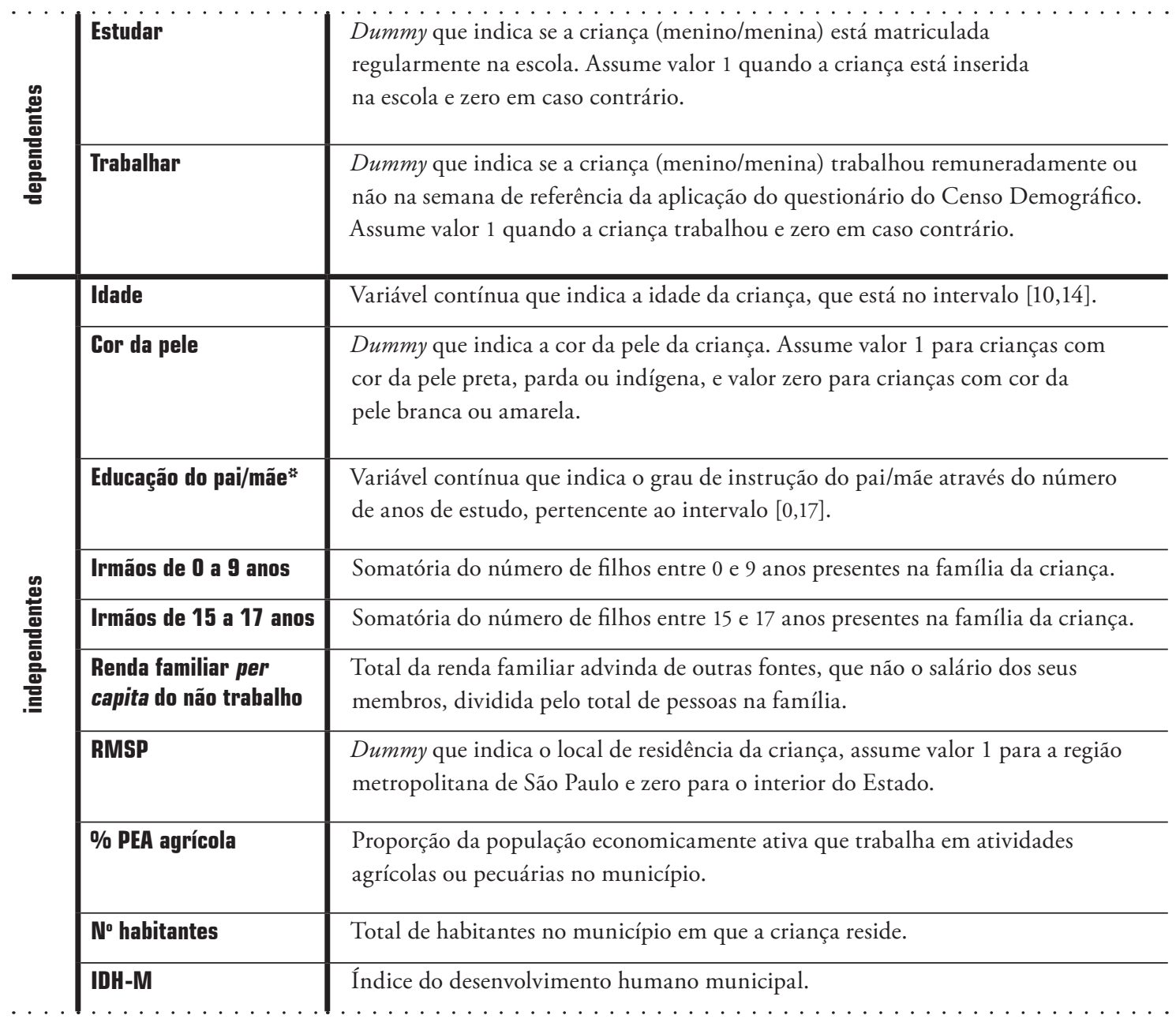

Fonte: elaboração própria 
Tabela 5.1 - Probit bivariado segundo gênero - Pais com mesma condição de migração

(continua)

\begin{tabular}{|c|c|c|c|c|c|c|c|c|}
\hline \multirow{2}{*}{ Probit bivariado } & \multicolumn{2}{|c|}{ Não migrante } & \multicolumn{2}{|c|}{ Migrante CP } & \multicolumn{2}{|c|}{ Paulista retornado } & \multicolumn{2}{|c|}{ Migrante LP } \\
\hline & Menino & Menina & Menino & Menina & Menino & Menina & Menino & Menina \\
\hline \multicolumn{9}{|l|}{ Estudar } \\
\hline Idade & $-0,1199^{* *}$ & $-0,1493^{* *}$ & $-0,0963^{* *}$ & $-0,1011^{* *}$ & $-0,2051^{*}$ & 0,1223 & $-0,0794^{* *}$ & $-0,1535^{* *}$ \\
\hline Cor & $-0,0375$ & $-0,0609$ & $-0,0899$ & $-0,0350$ & $-0,1402$ & 0,1307 & 0,0040 & $-0,0240$ \\
\hline Irmáos de 0 a 9 anos & $-0,1577^{* *}$ & $-0,1085^{*}$ & $-0,0618$ & $-0,1274$ & $1,1958^{*}$ & $6,1150^{*}$ & $-0,1001^{*}$ & $-0,1176^{* *}$ \\
\hline Irmãos de 15 a 17 anos & $-0,0798^{* *}$ & $-0,0109$ & $-0,1097^{*}$ & $-0,0383$ & $-0,1629$ & $-0,5347^{*}$ & $-0,0324$ & $-0,0353$ \\
\hline Anos de estudo - pai & $0,0425^{* *}$ & $0,0440^{* *}$ & $0,0409^{* *}$ & $0,0271^{*}$ & 0,0366 & 0,0288 & $0,0289^{* *}$ & $0,0301^{* *}$ \\
\hline Anos de estudo - mãe & $0,0528^{* *}$ & $0,0476^{* *}$ & $0,0372^{* *}$ & $0,0256^{* *}$ & $0,0984^{* *}$ & $-0,0125$ & $0,0339^{* *}$ & $0,0324^{* *}$ \\
\hline $\mathrm{RPC}-\mathrm{NT}^{*}$ & 0,0117 & 0,0130 & $-0,0012$ & 0,1270 & $0,7261^{*}$ & 0,1352 & 0,0283 & 0,0455 \\
\hline RMSP & 0,0404 & $-0,0596$ & $-0,1833^{*}$ & $-0,1134$ & 0,4881 & $-0,2429$ & $-0,0024$ & $-0,0365$ \\
\hline \% PEA agrícola & $0,0046^{*}$ & $0,0044^{*}$ & $-0,0032$ & $-0,0028$ & $-0,0171$ & $-0,0080$ & 0,0045 & $-0,0016$ \\
\hline No habitantes & $-1,7 \mathrm{E}-07^{* *}$ & $-1,5 \mathrm{E}-07^{* *}$ & $-3,6 \mathrm{E}-08$ & $-2,4 \mathrm{E}-07^{*}$ & $-3,1 \mathrm{E}-07$ & $-1,3 \mathrm{E}-06^{* *}$ & $-1,1 \mathrm{E}-07^{*}$ & $-1,3 \mathrm{E}-07^{* *}$ \\
\hline IDH-M & $1,7471^{* *}$ & $2,6536^{* *}$ & $-0,0246$ & 0,1429 & $-8,8340$ & 11,1391 & 0,4834 & 0,6668 \\
\hline Constante & $1,5067^{* *}$ & $1,2285^{* *}$ & $2,8400^{* *}$ & $2,8622^{*}$ & $10,8959^{*}$ & $-7,4759$ & $2,2616^{* *}$ & $3,1764^{* *}$ \\
\hline \multicolumn{9}{|l|}{ Trabalhar } \\
\hline Idade & $0,3155^{* *}$ & $0,2977^{* *}$ & $0,3154^{* *}$ & $0,3555^{* *}$ & $0,3731^{* *}$ & $0,2693^{*}$ & $0,2595^{* *}$ & $0,2687^{* *}$ \\
\hline Cor & $-0,0013$ & 0,0503 & $-0,0138$ & 0,0610 & 0,0153 & $-0,4544$ & $0,0763^{*}$ & $-0,0435$ \\
\hline Irmáos de 0 a 9 anos & $0,1665^{* *}$ & 0,0585 & 0,0380 & 0,1767 & $-5,9045^{*}$ & $-6,7987^{*}$ & 0,0414 & $0,1370^{*}$ \\
\hline Irmãos de 15 a 17 anos & $-0,0360$ & $0,0678^{* *}$ & 0,0113 & 0,0614 & $-0,2996$ & $0,3920^{*}$ & 0,0252 & 0,0253 \\
\hline Anos de estudo - pai & $-0,0189^{* *}$ & $-0,0190^{* *}$ & $-0,0014$ & $-0,0339^{*}$ & $-0,0275$ & $-0,0442$ & $-0,0120^{*}$ & $-0,0159^{*}$ \\
\hline Anos de estudo - mãe & $-0,0153^{* *}$ & $-0,0198^{* *}$ & $-0,0113$ & $-0,0050$ & $-0,0458$ & $-0,0365$ & $-0,0162^{* *}$ & $-0,0048$ \\
\hline $\mathrm{RPC}-\mathrm{NT}^{*}$ & $-0,0169$ & $-0,0515^{*}$ & $-0,3642^{*}$ & 0,0326 & $-0,3262$ & $-0,2120$ & 0,0103 & $-0,0949^{*}$ \\
\hline RMSP & $-0,1227^{* *}$ & $-0,0946$ & $-0,2713^{* *}$ & $-0,2753^{* *}$ & $-7,6835$ & $-0,0455$ & $-0,1309^{*}$ & $-0,1815^{* *}$ \\
\hline \% PEA agrícola & $0,0091^{* *}$ & $0,0052^{* *}$ & $-0,0029$ & $0,0109^{* *}$ & 0,0135 & $-0,0052$ & 0,0048 & $0,0114^{* *}$ \\
\hline No habitantes & $-3,7 \mathrm{E}-08$ & 0,0000 & $2,2 \mathrm{E}-07$ & 0,0000 & $7,2 \mathrm{E}-06$ & $5,2 \mathrm{E}-07$ & 0,0000 & 0,0000 \\
\hline IDH-M & $-0,1332$ & $-0,2081$ & $-1,9479$ & 2,7172 & 1,9798 & 14,0921 & $-1,1148$ & 0,7962 \\
\hline Constante & $-5,5566^{* *}$ & $-5,4382^{* *}$ & $-4,0093^{* *}$ & $-8,5310^{* *}$ & $-7,6498$ & $-16,8776^{*}$ & $-4,1399^{* *}$ & $-6,0257^{* *}$ \\
\hline
\end{tabular}




\begin{tabular}{|c|c|c|c|c|c|c|c|c|}
\hline \multirow{2}{*}{ Probit bivariado } & \multicolumn{2}{|c|}{ Não migrante } & \multicolumn{2}{|c|}{ Migrante CP } & \multicolumn{2}{|c|}{ Paulista retornado } & \multicolumn{2}{|c|}{ Migrante LP } \\
\hline & Menino & Menina & Menino & Menina & Menino & Menina & Menino & Menina \\
\hline lathrho & $-0,2664^{* *}$ & $-0,2530^{* *}$ & $-0,3073^{* *}$ & $-0,3424^{* *}$ & $-0,2430$ & $-0,5640$ & $-0,3624^{* *}$ & $-0,2644^{* *}$ \\
\hline Rho & $-0,2603$ & $-0,2477$ & $-0,2980$ & $-0,3296$ & $-0,2384$ & $-0,5110$ & $-0,3473$ & $-0,2584$ \\
\hline Wald chi2 $(20)=$ & 1.656 & 1.176 & 255 & 192 & 1.012 & 1.390 & 467 & 407 \\
\hline Log. Pseud. = & -106.160 & -82.583 & -17.648 & -14.040 & -1.382 & -659 & -57.474 & -43.493 \\
\hline \multicolumn{9}{|l|}{ Wald test $/$ rho $=0$} \\
\hline Chi $2(1)=$ & 96,92 & 60,66 & 23,15 & 22,50 & 1,53 & 3,22 & 10,28 & 34,20 \\
\hline Prob. $>$ chi $2=$ & 0,0000 & 0,0000 & 0,0000 & 0,0000 & 0,2154 & 0,0729 & 0,0000 & 0,0000 \\
\hline \multicolumn{9}{|l|}{ Probabilidades } \\
\hline Só est p(10) & 95,29 & 96,45 & 92,94 & 94,11 & 94,62 & 97,90 & 94,85 & 96,15 \\
\hline Trab \& est $\mathrm{p}(11)$ & 2,64 & 1,71 & 2,87 & 1,90 & 2,68 & 0,88 & 2,37 & 1,48 \\
\hline Só trab p $(01)$ & 0,25 & 0,16 & 0,48 & 0,37 & 0,44 & 0,12 & 0,35 & 0,17 \\
\hline Náo trab e não est p(00) & 1,82 & 1,67 & 3,71 & 3,62 & 2,26 & 1,10 & 2,43 & 2,20 \\
\hline ESTUDA & 97,93 & 98,17 & 95,81 & 96,01 & 97,30 & 98,78 & 97,22 & 97,63 \\
\hline TRABALHA & 2,89 & 1,87 & 3,35 & 2,26 & 3,13 & 1,00 & 2,72 & 1,65 \\
\hline
\end{tabular}

* RPC $-\mathrm{NT}=$ renda familiar per capita nấo advinda do trabalho

** nível significância de 1\% /* nível significância de 5\%

Tabela 5.2 - Probit bivariado segundo gênero - Mães em famílias monoparentais sob sua responsabilidade

(continua)

\begin{tabular}{|c|c|c|c|c|c|c|c|c|}
\hline \multirow{2}{*}{ Probit bivariado } & \multicolumn{2}{|c|}{ Não migrante } & \multicolumn{2}{|c|}{ Migrante CP } & \multicolumn{2}{|c|}{ Paulista retornado } & \multicolumn{2}{|c|}{ Migrante LP } \\
\hline & Menino & Menina & Menino & Menina & Menino & Menina & Menino & Menina \\
\hline \multicolumn{9}{|l|}{ Estudar } \\
\hline Idade & $-0,1724^{* *}$ & $-0,1806^{* *}$ & $-0,1164^{* *}$ & $-0,2213^{* *}$ & $-0,3959^{* *}$ & $-0,0093$ & $-0,1720^{* *}$ & $-0,1384^{* *}$ \\
\hline Cor & $-0,1038^{* *}$ & $-0,0402$ & $-0,1314$ & 0,0941 & $0,8045^{*}$ & 0,0319 & $-0,0154$ & 0,0655 \\
\hline Irmãos de 0 a 9 anos & $-0,0475$ & $-0,0278$ & 0,0085 & $-0,1367$ & 0,4798 & $-0,1982$ & $-0,0362$ & $-0,0658$ \\
\hline Irmãos de 15 a 17 anos & $-0,0515$ & $-0,0526$ & $-0,0739$ & $-0,0143$ & $-0,0616$ & $-0,0773$ & $-0,0769$ & $-0,0284$ \\
\hline Anos de estudo - mãe & $0,0742^{* *}$ & $0,0656^{* *}$ & $0,0427^{* *}$ & $0,0482^{* *}$ & $0,1804^{* *}$ & $0,1091^{*}$ & $0,0511^{* *}$ & $0,0575^{* *}$ \\
\hline $\mathrm{RPC}-\mathrm{NT}^{*}$ & $0,1528^{* *}$ & $0,1112^{* *}$ & 0,2506 & 0,0313 & 1,2283 & $-0,0748$ & $-0,0072$ & 0,0243 \\
\hline RMSP & $0,2004^{*}$ & $0,1908^{*}$ & 0,1848 & $-0,0024$ & 0,3366 & 0,2620 & $-0,0171$ & $-0,1531$ \\
\hline
\end{tabular}




\begin{tabular}{|c|c|c|c|c|c|c|c|c|}
\hline \multirow{2}{*}{ Probit bivariado } & \multicolumn{2}{|c|}{ Não migrante } & \multicolumn{2}{|c|}{ Migrante CP } & \multicolumn{2}{|c|}{ Paulista retornado } & \multicolumn{2}{|c|}{ Migrante LP } \\
\hline & Menino & Menina & Menino & Menina & Menino & Menina & Menino & Menina \\
\hline \% PEA agrícola & 0,0044 & 0,0020 & $0,0449^{* *}$ & 0,0058 & $0,0842^{*}$ & 0,0357 & $-0,0068$ & $-0,0155^{* *}$ \\
\hline No habitantes & $-2,90 \mathrm{E}-07^{* *}$ & $-3,78 \mathrm{E}-07^{* *}$ & $-3,79 \mathrm{E}-08$ & $-4,91 \mathrm{E}-08$ & $-8,20 \mathrm{E}-07$ & $-7,63 \mathrm{E}-07$ & \begin{tabular}{|l|}
$-1,58 \mathrm{E}-07^{*}$ \\
\end{tabular} & $-1,14 \mathrm{E}-07$ \\
\hline IDH-M & $2,0399^{* *}$ & $2,3792^{* *}$ & 1,3699 & 1,1161 & $-2,5370$ & 6,2214 & 0,6721 & $-0,9707$ \\
\hline Constante & $1,7655^{*}$ & 1,7864 & 1,4471 & 3,2416 & 6,9996 & $-3,6590$ & $3,2026^{* *}$ & $4,2344^{* *}$ \\
\hline \multicolumn{9}{|l|}{ Trabalhar } \\
\hline Idade & $0,3089^{* *}$ & $0,3210^{* *}$ & $0,2386^{* *}$ & $0,4089^{* *}$ & $0,5588^{* *}$ & $0,3170^{* *}$ & $0,2852^{* *}$ & $0,3143^{* *}$ \\
\hline Cor & $-0,0097$ & $-0,0132$ & $-0,1040$ & $-0,1032$ & $-0,2651$ & $-0,1717$ & 0,0158 & 0,0012 \\
\hline Irmãos de 0 a 9 anos & $0,1287^{* *}$ & 0,0442 & $-0,0092$ & $-0,0385$ & $-0,1259$ & $-0,2710$ & $0,1478^{* *}$ & $-0,0443$ \\
\hline Irmãos de 15 a 17 anos & $-0,0433$ & $0,0949^{*}$ & $-0,1783$ & $-0,0047$ & 0,1114 & $-0,0329$ & $-0,0127$ & 0,0091 \\
\hline Anos de estudo - mãe & $-0,0191^{* *}$ & $-0,0334^{* *}$ & $-0,0078$ & $-0,0053$ & $-0,0586$ & $-0,0234$ & $-0,0270^{* *}$ & $-0,0272^{* *}$ \\
\hline $\mathrm{RPC}-\mathrm{NT}^{*}$ & $-0,1668^{* *}$ & $-0,0193$ & $-0,0762$ & 0,0115 & $-0,0443$ & $-0,2546$ & $-0,0591$ & $-0,1598^{*}$ \\
\hline RMSP & $-0,1283$ & $-0,1132$ & $-0,0335$ & $-0,0661$ & $-0,7297$ & $-0,5763$ & $-0,2236^{*}$ & $-0,0338$ \\
\hline \% PEA agrícola & $0,0098^{* *}$ & $0,0099^{* *}$ & $-0,0034$ & 0,0143 & $-0,0223$ & $-0,0110$ & 0,0049 & 0,0086 \\
\hline No habitantes & $1,64 \mathrm{E}-08$ & $-4,05 \mathrm{E}-08$ & $-2,68 \mathrm{E}-07$ & $-3,47 \mathrm{E}-08$ & $5,70 \mathrm{E}-07$ & $3,32 \mathrm{E}-08$ & $6,60 \mathrm{E}-08$ & $-6,38 \mathrm{E}-08$ \\
\hline IDH-M & 1,1473 & 0,4794 & 0,2813 & 5,3422 & $-6,0094$ & $10,6018^{*}$ & 2,3834 & 0,6884 \\
\hline Constante & $-6,4995^{* *}$ & $-6,2181^{* *}$ & $-4,6897^{*}$ & $-11,3576^{* *}$ & $-3,4375$ & $-13,7100^{*}$ & $-7,1779^{* *}$ & $-6,2291^{* *}$ \\
\hline /athrho & $-0,3034^{* *}$ & $-0,2761^{* *}$ & $-0,4679^{* *}$ & $-0,1819$ & $-0,0123$ & $-0,9249^{* *}$ & $-0,3492^{* *}$ & $-0,2880^{* *}$ \\
\hline Rho & $-0,2944$ & $-0,2693$ & $-0,4365$ & $-0,1800$ & $-0,0123$ & $-0,7282$ & $-0,3356$ & $-0,2803$ \\
\hline No Obs. = & 13.368 & 13.440 & 1.367 & 1.627 & 340 & 336 & 7.387 & 7.432 \\
\hline Wald chi2 $(20)=$ & 557 & 409 & 65 & 89 & 63,27 & 95 & 243,76 & 208 \\
\hline Log. Pseud. = & -35.602 & -29.646 & -5.103 & -5.038 & -666 & -826 & -22.238 & -20.044 \\
\hline \multicolumn{9}{|l|}{ Wald test $/$ rho $=0$} \\
\hline Chi $2(1)=$ & 51,90 & 31,05 & 18,41 & 2,98 & 0,0020 & 5,82 & 41,95 & 21,94 \\
\hline Prob. $>$ chi $2=$ & 0,0000 & 0,0000 & 0,0000 & 0,0841 & 0,9645 & 0,0159 & 0,0000 & 0,0000 \\
\hline \multicolumn{9}{|l|}{ Probabilidades } \\
\hline Só est $\mathrm{p}(10)$ & 92,88 & 94,46 & 89,95 & 91,56 & 93,39 & 93,32 & 92,40 & 93,54 \\
\hline Trab \& est $\mathrm{p}(11)$ & 3,05 & 2,41 & 2,82 & 2,67 & 2,72 & 3,95 & 2,97 & 2,61 \\
\hline Só trab p(01) & 0,58 & 0,37 & 1,12 & 0,49 & 0,41 & 0,91 & 0,69 & 0,43 \\
\hline Não trab e náo est p $(00)$ & 3,49 & 2,76 & 6,10 & 5,28 & 3,48 & 1,81 & 3,94 & 3,42 \\
\hline ESTUDA & 5,94 & 96,87 & 92,77 & 94,23 & 96,11 & 97,27 & 95,37 & 96,15 \\
\hline $\begin{array}{l}\text { TRABALHA } \\
. \ldots\end{array}$ & 3,63 & 2,78 & 3,94 & 3,16 & 3,13 & 4,87 & 3,66 & 3,05 \\
\hline
\end{tabular}

* RPC $-\mathrm{NT}=$ renda familiar per capita não advinda do trabalho

** nível significância de $1 \%$ / * nível significância de 5\% 
Esse resultado valida a escolha do método econométrico e reafirma que as duas decisóes têm algum grau de associação, por isso devem ser estimadas em conjunto. No entanto, esse vínculo não excludente entre as duas escolhas - escola e trabalho - não nos permite estabelecer nenhuma relação causal.

Os resultados básicos referentes à probabilidade de trabalhar reafirmam a literatura especializada: as chances de trabalhar crescem com a idade, são maiores entre os meninos, diminuem conforme a escolaridade dos pais aumenta, são influenciadas pela quantidade de irmãos mais novos e são especialmente elevadas em famílias monoparentais sob responsabilidade de mulheres. ${ }^{30}$ No entanto, esses resultados devem ser analisados de acordo com a condição migratória, uma vez que esta característica é bastante relevante para a definição de padróes familiares. ${ }^{31}$
O trabalho de Barros e Mendonça (1990b) indica que os principais fatores que explicam a relaçáo positiva entre a idade da criança e o crescimento da sua inserção no mercado de trabalho brasileiro são: maior atratividade do mercado de trabalho conforme a criança cresce, redução da atratividade da escola (repetência e/ou insatisfação com o sistema educacional) e necessidade de maior independência por parte da criança.

Ao analisar o impacto da idade nas chances de a criança trabalhar percebe-se que, apesar da relação continuar positiva, a condição de migração do responsável interfere na magnitude da resposta de acordo com o gênero da criança. Assim, o impacto positivo da idade sobre a probabilidade de trabalhar é maior para as meninas que para os meninos quando eles são filhos de migrantes de curto e longo prazo, ao contrário do que indica a literatura da

$\begin{array}{ll}{ }^{30} \text { Veja-se Barros e Mendonça } & \text { Os trabalhos de Bilac (1997) } \\ \text { (1990a, 1990b), Cervini e } & \text { e Montali (1997) analisaram } \\ \text { Burger (1991), Kassouf (1999), } & \text { a diferenciação de padrôes } \\ \text { (2000), Muniz (2001). } & \text { familiares dos domicílios } \\ & \text { chefiados por migrantes e } \\ & \text { não migrantes no estado de } \\ & \text { São Paulo. Esses trabalhos }\end{array}$

${ }^{30}$ Veja-se Barros e Mendonça (1990a, 1990b), Cervini e Azêvedo, Menezes e Fernandes (2000), Muniz (2001).

\author{
mostraram que a estrutura \\ e a organização familiar de \\ domicílios chefiados por \\ migrantes podem ser distintas \\ daquelas dos não migrantes, \\ porque essas duas classes de \\ famílias se encontram em
} momentos diferentes do ciclo familiar. De acordo com Montali (1997), a grande maioria das famílias migrantes geralmente está concentrada em momentos iniciais do ciclo de vida familiar em relação às não migrantes. 
${ }^{32}$ Exceção são os filhos de mães retornadas.

${ }^{33}$ Maior impacto negativo entre todas as crianças. área. Por outro lado, em famílias monoparentais, a probabilidade de a criança trabalhar quando fica mais velha também é maior para as meninas que para os meninos, independentemente da condição de migração da mãe. ${ }^{32}$ Seguindo os argumentos de Barros e Mendonça (1990b), parece que a atratividade do mercado de trabalho para os filhos de migrantes é maior para as meninas que para os meninos.

O papel da escolaridade dos pais migrantes também apresentou algumas especificidades em relação aos resultados já estabelecidos. O trabalho de Kassouf (1999) já tinha apontado que, apesar do impacto negativo da escolaridade dos pais na probabilidade de trabalhar dos filhos, essa influência ocorre de maneira diferenciada para meninos e meninas, dependendo ainda do gênero do cônjuge. De acordo com a autora, enquanto a escolaridade do pai tem maior impacto em reduzir a participação do filho na força de trabalho com relação à da mãe, no caso da filha as escolaridades de pai e mãe têm efeitos semelhantes. No entanto, esse resultado só se confirmou para os filhos de não migrantes, pois no caso das crianças cujo responsável é migrante o impacto da escolaridade dos pais se mostrou mais desafiador.
Para os filhos de casais com a mesma condição de migração, os resultados da tabela 5.1 mostram que a escolaridade dos pais náo surte efeito algum sobre a probabilidade de trabalhar das crianças de pais retornados, independentemente do gênero. Nos outros casos temos que, apesar da escolaridade do pai migrante de curto prazo não fazer diferença alguma para o menino, diminuiu consideravelmente as chances de suas filhas trabalharem. ${ }^{33}$ Para os filhos de migrantes de longo prazo, tanto a escolaridade dos pais quanto a das mães diminui as chances do menino trabalhar, mas a probabilidade de trabalhar das filhas não sofre influência da instrução de suas mães.

Quanto às famílias monoparentais, os resultados da Tabela 5.2 mostram que a escolaridade das mães diminui as chances de trabalhar apenas dos filhos das não migrantes e das migrantes de longo prazo, sendo as meninas as maiores beneficiadas. $\mathrm{O}$ grau de instrução das mães migrantes de curto prazo e das retornadas não influi na probabilidade de seus filhos trabalharem.

O trabalho de Kassouf (1999) também conclui que ter irmãos mais novos aumenta as chances de a criança trabalhar. No presente estudo, constatamos que a proxy para irmãos mais novos vai 
ao encontro aos resultados da autora somente em alguns casos: filhos de pais não migrantes e filhas de pais migrantes de longo prazo, para casais com a mesma condição de migração. Em lares monoparentais a relação apontada por Kassouf se mantém, independentemente do gênero da criança, somente nas famílias chefiadas por mães não migrantes e migrantes de longo prazo.

A relevância da chefia feminina seguiu os resultados já encontrados por Muniz (2001), apontando que estar em um lar monoparental aumenta consideravelmente as chances de qualquer criança trabalhar, independentemente do gênero e da condição de migração do seu responsável. Nesse caso, as filhas de mães retornadas são as mais prejudicadas.

As probabilidades previstas de estudar/trabalhar de meninos e meninas não são muito discrepantes das apresentadas na Tabela 4. Por outro lado, a probabilidade de trabalhar dos filhos de mães migrantes de curto prazo, com ou sem cônjuge, aumenta. Desse modo, podemos afirmar que o probit bivariado corrige as probabilidades de estudar/ trabalhar para toda a amostra, antes de aplicarmos o conjunto das variáveis explicativas dos filhos de não migrantes na estimação dos filhos das três categorias de migrantes.
A Tabela 6 mostra o resultado referente ao diferencial das probabilidades de estudar/trabalhar de meninos e meninas de acordo com a tipologia familiar utilizada. Os resultados indicam que a grande maioria das crianças de mães migrantes (curto prazo, longo prazo ou retornadas), independentemente do tipo de família, possui probabilidade de estudar inferior à dos filhos das paulistas não migrantes. ${ }^{34}$

No que diz respeito à probabilidade de trabalhar, percebem-se duas tendências:

1. os filhos de casal migrante de curto-prazo possuem maiores chances de ofertar trabalho;

2. as mães migrantes com família monoparental sob sua responsabilidade, independentemente do tempo de residência no estado de São Paulo, a despeito da vantagem apresentada na equação de rendimentos, inserem os filhos no mercado de trabalho numa proporção maior que as mães paulistas não migrantes.

Com o intuito de responder às questôes levantadas até aqui, a análise da decomposição do diferencial será realizada de acordo com o tipo de família na qual a criança está inserida.

\footnotetext{
${ }^{34}$ As exceçóes são os filhos das paulistas retornadas sem cônjuge e as meninas de casais retornados.
} 
Tabela 6 - Diferencial das probabilidades de estudar/trabalhar por tipo de família - em \%

\begin{tabular}{|c|c|c|c|c|c|c|}
\hline \multirow[t]{2}{*}{ Tipo de família } & \multicolumn{2}{|c|}{ Mãe migrante CP } & \multicolumn{2}{|c|}{ Mãe retornada } & \multicolumn{2}{|c|}{ Mãe migrante LP } \\
\hline & Menino & Menina & Menino & Menina & Menino & Menina \\
\hline \multicolumn{7}{|c|}{ Probabilidade de Estudar } \\
\hline $\begin{array}{l}\text { Casal - condição } \\
\text { de migração igual }\end{array}$ & $-2,12$ & $-2,15$ & $-0,63$ & 0,61 & $-0,71$ & $-0,54$ \\
\hline Mãe sem cônjuge & $-3,16$ & $-2,64$ & 0,18 & 0,40 & $-0,57$ & $-0,72$ \\
\hline \multicolumn{7}{|l|}{$\begin{array}{c}\text { Probabilidade de } \\
\text { Trabalhar }\end{array}$} \\
\hline $\begin{array}{l}\text { Casal - condição } \\
\text { de migração igual }\end{array}$ & 0,45 & 0,39 & 0,23 & $-0,87$ & $-0,18$ & $-0,22$ \\
\hline Mãe sem cônjuge & 0,31 & 0,38 & $-0,50$ & 2,09 & 0,03 & 0,27 \\
\hline
\end{tabular}

Valor positivo indica que a probabilidade dos filhos de migrantes é maior que a dos năo migrantes, e valor negativo o contrário. Fonte: Tabelas 5.1 e 5.2 .

\section{1_Pais com mesma condição de migração}

A maior parte da amostra concentrase nas famílias cujos pais têm a mesma condição de migração, o que representa $80,4 \%$ das crianças. Sabe-se que o deslocamento tanto dos migrantes de curto prazo quanto dos retornados pode ser considerado de ordem familiar (Tabela 2), situação que náo se aplica para os migrantes de longo prazo. No caso de casais migrantes de longo prazo, apenas $28,7 \%$ dos filhos entre 10 e 14 anos vieram de outra Unidade da Federação, sendo que a grande maioria - 71,3\% nasceu no local de destino do deslocamento dos pais.
Essa situação resulta em probabilidades diferentes de as crianças trabalharem. A Tabela 6.1a mostra que os filhos de migrantes de longo prazo possuem menor probabilidade de trabalhar que os filhos de não migrantes. Apesar de o componente não explicado, nessa situação, ser preponderante apenas no caso dos meninos, esse resultado se relaciona com a seletividade positiva de pais e mães migrantes de longo prazo no local de destino.

Esse resultado reflete o fato de que os filhos de migrantes de longo prazo náo precisam arcar com o custo de adaptação ao local de destino dos pais. Por isso, a decisão de alocação do tempo dessas crianças entre escola e trabalho não sofre 
Tabela 6.1a: Decomposição do diferencial Probit bivariado Pais com mesma condição de migração - em \%

\begin{tabular}{c|c|c|c|c|c|c|c} 
Diferença em relação aos & \multicolumn{2}{|c}{ Migrante CP } & \multicolumn{2}{c}{ Retornado } & \multicolumn{2}{c}{ Migrante LP } \\
filhos dos não migrantes & Menino & Menina & Menino & Menina & Menino & Menina \\
\hline Probabilidade Estudar & $-2,12$ & $-2,15$ & $-0,63$ & 0,61 & $-0,71$ & $-0,54$ \\
\hline Explicada & $-1,97$ & $-1,62$ & 0,16 & 0,12 & $-1,09$ & $-0,89$ \\
\hline Náo explicada & $-0,15$ & $-0,54$ & $-0,78$ & 0,50 & 0,38 & 0,35 \\
\hline Probabilidade Trabalhar & 0,45 & 0,39 & 0,23 & $-0,87$ & $-0,18$ & $-0,22$ \\
\hline Explicada & 0,04 & 0,10 & $-0,14$ & $-0,20$ & 0,17 & $-0,21$ \\
\hline Não explicada & 0,42 & 0,29 & 0,37 & $-0,67$ & $-0,35$ & $-0,01$
\end{tabular}

Valor positivo indica que a probabilidade para os filhos de migrantes é maior que para os dos não migrantes, e valor negativo o contrário.

uma interferência tão acentuada do risco gerencial da renda (GROOTAERT e KANBUR, 1995) relacionado à insegurança dos pais de encontrar ou náo trabalho ou, ainda, da situação de instabilidade deste, marcante nos migrantes de curto prazo.

Assim, os filhos de migrantes de longo prazo acabam se beneficiando indiretamente das escolhas realizadas pelos pais, os quais, confirmando a hipótese de seletividade positiva, auferem rendimentos mais elevados que os próprios paulistas não migrantes (FERREIRA-BATISTA, 2006). Devido à sua situação economicamente superior, esse tipo de família não precisa ofertar o trabalho de seus filhos na mesma magnitude que as famílias paulistas.

No outro extremo, os filhos dos migrantes de curto prazo mostram uma posição de desvantagem frente aos filhos dos não migrantes. Essa diferença é explicada pelo componente não observado que se refere à condição de migração, comparada neste trabalho com os problemas de adaptação dos pais ao mercado de trabalho local.

Os resultados obtidos por Ferreira-Batista (2006), referentes à diferença dos rendimentos das três categorias de migrantes e não migrantes, apontam que, no caso dos pais migrantes de curto prazo, a vantagem das características pessoais não observadas não consegue compensar a valoração abaixo da média que o mercado faz de seus respectivos atributos. Por esse motivo, seus rendimentos são inferiores com relação aos dos pais não migrantes, e consequentemente, seus filhos apresentam maiores probabilidades de 
serem precocemente inseridos no mercado de trabalho, quando comparados aos filhos de pais paulistas não migrantes.

No que diz respeito aos filhos de pais retornados, constata-se que a baixa taxa de trabalho infantil apresentada (Tabela 4) reflete particularmente a situação das meninas, que têm chances de trabalhar menores que as filhas dos pais não migrantes. Nesse caso, os pais também são negativamente selecionados em relação aos não migrantes, mas, ao contrário da família de migrantes de curto prazo, esta categoria parece discriminar as crianças de acordo com o gênero, ao optar por encaminhar os meninos ao trabalho e as meninas à escola, uma vez que a taxa de trabalho infantil de meninos e meninas é de 3,23\% e $1,07 \%$, respectivamente. Em ambas as decisôes, o componente não explicado a condição de migração - pesa mais que as variáveis independentes.

Esta escolha pela frequência escolar em detrimento da possibilidade de trabalhar no caso de filhas de pais retornados chama a atenção, pois é o único caso, nesse tipo de família, em que a diferença da probabilidade de estudar em relação a filhos de não migrantes é positiva. Essa diferença aponta que as crianças, quando são poupadas do exercício de atividades econômicas, nem sempre são encaminha- das à escola. A seletividade positiva dos migrantes de longo prazo no local de destino evita, em parte, que seus filhos trabalhem, mas não é suficiente para que a frequência escolar seja maior com relação aos filhos dos não migrantes. Além disso, notamos que nos casos de famílias migrantes de curto e longo prazo a maior parte da diferença da probabilidade de estudar com relação aos filhos de não migrantes ocorre devido às características observáveis de pais e filhos.

Com relação à decomposição, constatamos também que o sinal do componente não explicado se inverte quando comparamos os filhos de migrantes de curto prazo e de longo prazo. Essa distinção reflete o impacto no local de destino da seletividade positiva no caso de migrantes de longo prazo, os quais ainda assim carregam características que não colaboram para a inserção escolar ou a continuidade dos estudos dos filhos.

\section{2_Mães com famílias monoparentais sob sua responsabilidade}

No estado de São Paulo, aproximadamente $16 \%$ das crianças entre 10 e 14 anos vivem em lares sem pai. Nessas circunstâncias, em geral, as mães passam a ser o principal provedor familiar, e sua remuneração advinda do trabalho é fundamental para evitar que seus filhos se- 
jam inseridos precocemente no trabalho. Devido à falta de um companheiro com quem compartilhar a responsabilidade de gerenciamento da família, a proporção de mães nessa situação que participam do mercado de trabalho é $22,5 \%$ maior em relação àquelas que possuem cônjuge. Ao todo, perfazem $66 \%$ de mães que trabalham, sendo que a maior taxa de participação ocorre na categoria de mães migrantes de curto prazo (68\%).

Apesar da decomposição da equação de rendientos dos pais dessas crianças, presente em Ferreira-Batista (2006), ter mostrado que a dimensão positiva das características pessoais não observáveis é maior que a discriminação negativa que o mercado de trabalho faz da situação de migração das mães migrantes em relação às não migrantes, a Tabela $6.1 \mathrm{~b}$ aponta que essa diferença a favor do primeiro grupo não implica menor probabilidade dos seus filhos trabalharem em relação à dos filhos do segundo. ${ }^{35}$

A maior probabilidade de oferta da mão de obra dos filhos das mães migrantes não pode ser atribuída à sua dificuldade em se inserir no mercado de trabalho, mas sim à posição da ocupação dessas mães migrantes.

Enquanto a diferença positiva entre as probabilidades de trabalhar dos filhos das mães migrantes de curto prazo e das não migrantes é mantida pela condição de migraçáo, no caso das mães migrantes de longo prazo a discrepância deve-se às variáveis explicativas. Além disso, os dados mostram que as filhas de mães migrantes de longo prazo não se beneficiam tanto quanto os meninos do fato de não precisarem arcar com parte do custo de adaptação familiar no local de destino. Esse resultado associa-se à distribuição da ocupação dentre as mulheres migrantes. Dentre as mães migrantes de curto prazo, aproximadamente $40 \%$ das que trabalham ocupam-se de serviços domésticos, contra 32\% das mães migrantes de longo prazo e, ainda, apenas $21 \%$ das náo migrantes. Como as mães migrantes de longo prazo um dia já foram migrantes de curto-prazo, é plausível levantar a hipótese de que as filhas de domésticas tenham sido encaminhadas para a mesma ocupação de suas mães. ${ }^{36}$

O tipo de atividade desempenhada pelas mães no mercado de trabalho traz informaçóes importantes quanto às facilidades de inserção precoce de seus filhos, como, por exemplo, o tipo de qualificação que os pais devem estimular na criança desde cedo e ainda as possibilidades de emprego disponíveis. No caso das mães sem cônjuge domésticas, o seu conhecimento a respeito de mercado de trabalho é facilmente aplicado a suas filhas.

\footnotetext{
${ }^{35}$ A autora atribui este resultado ao fato de que grande parte das mulheres migrantes são trabalhadoras domésticas, cuja renda não pode ser devidamente captada pela variável anos de estudo.

${ }^{36}$ Essa possibilidade advém do fato de que o mercado de trabalho para serviços domésticos tem uma alta dependência das redes sociais. Nessa atividade, a prática de contratação tem forte correlação com a extensão da rede de contatos tanto de empregadores quanto de empregados.
} 
Tabela 6.1b: Decomposição do diferencial Probit bivariado Mães sem cônjuge - em \%

\begin{tabular}{|c|c|c|c|c|c|c|}
\hline \multirow{2}{*}{$\begin{array}{l}\text { Diferença em relação aos } \\
\text { não migrantes" }\end{array}$} & \multicolumn{2}{|c|}{ Mãe Migrante Cp } & \multicolumn{2}{|c|}{ Mãe retornada } & \multicolumn{2}{|c|}{ Mãe migrante LP } \\
\hline & Menino & Menina & Menino & Menina & Menino & Menina \\
\hline Probabilidade Estudar & $-3,16$ & $-2,64$ & 0,18 & 0,40 & $-0,57$ & $-0,72$ \\
\hline Explicada & $-2,75$ & $-1,37$ & 0,93 & 0,60 & $-0,99$ & $-0,83$ \\
\hline Não explicada & $-0,41$ & $-1,27$ & $-0,75$ & $-0,19$ & 0,43 & 0,11 \\
\hline Probabilidade Trabalhar & 0,31 & 0,38 & $-0,50$ & 2,09 & 0,03 & 0,27 \\
\hline Explicada & $-0,02$ & $-0,52$ & $-0,21$ & 0,12 & 0,22 & 0,25 \\
\hline Não explicada & 0,33 & 0,90 & $-0,29$ & 1,97 & $-0,19$ & 0,02 \\
\hline
\end{tabular}

Obs. ${ }^{*}$ Valor positivo indica que a probabilidade dos filhos de migrantes é maior que a dos nấo migrantes, e valor negativo o contrário. Fonte: Tabela 5.2 .

No que diz respeito às mães retornadas, as estimativas mostram que, mais uma vez, elas diferenciam o tratamento dado aos seus filhos com relação ao dado às suas filhas. Desta vez, as meninas não são poupadas do trabalho como os meninos. Em todas as categorias, o diferencial positivo da probabilidade de trabalhar das meninas é maior com relação aos meninos, mas no caso das mães retornadas a magnitude da discrepância chama a atenção.

Quanto à probabilidade de estudar, repete-se aqui o que ocorre com a maioria das famílias: com exceção dos filhos das mães retornadas, as demais crianças têm menores chances de estudar quando comparadas aos filhos das mães não migrantes, devido primordialmente às características observadas, dentre as quais o grau de instrução dos pais deve ser a de maior preponderância. Contudo, como no caso dos casais com a mesma condição de migração, o sinal da parcela não observada se altera de negativo para positivo quando se passa da situação de curto para longo prazo. Esse fato mostra que também as mães migrantes sem cônjuge vivenciam uma melhora de sua renda, conforme o tempo de residência no local de destino se amplia, tanto que a desvantagem quanto às chances de seus filhos estudarem é menor, ainda que náo supere o peso negativo de sua baixa escolaridade.

\section{6_Considerações Finais}

O presente trabalho mede os impactos de curto e de longo prazo que a decisão de migração dos pais acarreta na probabilidade de os filhos estudarem/trabalha- 
rem em relação às famílias que não migraram. Os resultados mostraram que ao unir as variáveis clássicas da determinação do trabalho infantil ao recorte referente à decisão de migração dos pais, tais como contexto familiar do deslocamento geográfico associado ao tempo de residência no local de destino, não se percebe uma discrepância tão acentuada entre as probabilidades de trabalhar dos filhos de migrantes e aquelas observadas entre as crianças dos não migrantes. ${ }^{37}$

Já a decomposição da diferença da probabilidade de estudar/trabalhar de acordo com o tempo de residência no local de destino dos pais/mães e ainda entre a parcela explicável e não explicável permite melhor compreensão das escolhas entre escola e trabalho no contexto do deslocamento geográfico da família. Por esse motivo, este trabalho aprofunda as evidências encontradas na literatura de oferta da máo de obra de crianças analisando os custos advindos da migração familiar, particularmente no que diz respeito à situação dos filhos.

De maneira geral, os resultados apontam que a situação da família, em especial dos filhos, não é indiferente em relação às perspectivas de inserção laboral do migrante no local de destino. Sendo assim, dependendo do período do ciclo de vida em que a criança se encontra, o impacto do deslocamento da família sobre sua trajetória estudo/trabalho pode ser positivo ou negativo. O impacto positivo foi constatado na menor probabilidade de ofertar o trabalho das crianças entre os filhos de casais de migrantes de longo prazo, os quais na grande maioria já nasceram no estado de São Paulo ou não estavam em idade escolar no momento da migração. ${ }^{38}$

Paralelamente à questão da oferta de trabalho de crianças, o cálculo da diferença da probabilidade de estudar traz um resultado náo reportado pela literatura especializada: todos os filhos cuja mãe é migrante com origem em outra UF, em família monoparental ou não, têm me-

\begin{tabular}{|c|c|c|}
\hline $\begin{array}{l}{ }^{37} \text { Os resultados mostram } \\
\text { que, dentre as famílias de } \\
\text { casais com a mesma condição } \\
\text { de migração, a maior } \\
\text { desvantagem da probabilidade } \\
\text { de trabalhar em relação às }\end{array}$ & $\begin{array}{l}\text { crianças de pais não migrantes } \\
\text { ocorre no caso dos filhos } \\
\text { de pais migrantes de curto } \\
\text { prazo, que computam uma } \\
\text { chance } 0,45 \% \text { maior de ter } \\
\text { ofertada sua mão de obra. Já } \\
\text { nas famílias monoparentais }\end{array}$ & $\begin{array}{l}\text { a maior desvantagem se } \\
\text { dá entre as filhas das mães } \\
\text { migrantes de curto prazo em } \\
\text { relação às filhas das paulistas } \\
\text { não migrantes, uma vez que } \\
\text { as primeiras possuem uma } \\
\text { probabilidade } 0,38 \% \text { maior de }\end{array}$ \\
\hline
\end{tabular}

${ }^{37}$ Os resultados mostram que, dentre as famílias de casais com a mesma condição de migraçáo, a maior de trabalhar em relação às

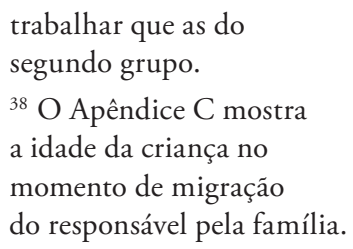


nos chances de estudar que os filhos das mães paulistas. De acordo com a decomposição dessa diferença, a discrepância se baseia nas características observáveis dos pais, em que o grau de instruçáo provavelmente é o fator mais importante.

O sinal positivo da parcela náo explicada da probabilidade de estudar dos filhos de migrantes de longo prazo, inclusive de famílias monoparentais, indica que existe melhora com relação à situação dos migrantes de curto prazo, porém ainda incapaz de reverter a posição desvantajosa. Nota-se que a seletividade positiva do migrante de longo prazo pode ser capaz de contribuir para um rendimento "controlado" maior, que diminui as chances de seu filho trabalhar. Porém, como essas crianças também têm menor probabilidade de estudar quando comparadas aos filhos dos paulistas, pode-se dizer que a melhora de condição de vida auferida pelo processo migratório de pais/mães não é integralmente transferida aos filhos.

Esse resultado vai ao encontro da literatura especializada sobre migração, a qual aponta que os migrantes conseguem melhorar sua renda e condiçóes ocupacionais com o avanço do tempo de residência. Entretanto, constatamos que esse avanço não é capaz de equipará-los aos não migrantes. Ou seja: a convergência da renda não acontece, pois desde crian- ças os filhos de migrantes têm uma probabilidade menor de frequentar a escola em relação aos filhos de não migrantes. No longo prazo, a inserção dessas crianças no mercado de trabalho deverá ocorrer de maneira precária, em ocupaçóes pouco qualificadas que dificilmente significarão avanço em relação à situação de seus pais, contribuindo para a manutenção do círculo intergeracional da pobreza.

O fato de este diferencial ser explicado por características observáveis impede a conclusão de que os filhos de migrantes de outra UF têm menor probabilidade de frequentar a escola, em virtude única e exclusivamente de terem seu percurso escolar prejudicado pelo processo migratório. Esse fator interfere no curto prazo, quando a criança também está envolvida na migração, mas sua dimensão é bem menor quando comparada ao peso das principais variáveis explicativas: idade, cor, número de irmãos mais novos e mais velhos, escolaridade dos pais, renda per capita do não trabalho e local de residência.

A desvantagem da frequência escolar dos filhos de casais migrantes de longo prazo, que não têm custos de adaptação, reafirma a importância do capital humano dos pais, apontando que este tem uma dimensão que vai além da capacidade de geração de renda. Muitas vezes o grau de instrução dos pais interfere 
na capacidade destes em ajudar a criança a transpor as dificuldades da vida escolar. Esse resultado é fundamental para que a estratégia de combate ao trabalho infantil seja refletida em termos de seus avanços de curto e de longo prazo, contrapondo-se o problema da insuficiência de renda no presente à capacidade futura de a criança conquistar um emprego quando adulta, bloqueando assim a transmissão da desvantagem para seus filhos.

Dessa maneira, o resultado encontrado para os migrantes de longo prazo aponta claramente que, mesmo existindo um choque positivo na renda familiar, nesse caso caracterizado pela migração dos pais, as crianças não necessariamente são enviadas à escola ou lá permanecem. Ou seja, mesmo que as crianças frequentem a escola e não trabalhem, o que garante a constância da sua vida escolar e seu efetivo sucesso encontra-se além do problema financeiro da família.

No presente estudo, três questôes ficam em aberto. Pontua-se particularmente a divergência da situação de bem-estar dos filhos de migrantes de longo prazo, que têm maiores chances de serem poupados da oferta de trabalho, mas mostram probabilidade menor de estudar. Apesar de os resultados terem explicitado que essa situação se deve às características observáveis, parece importante explorar em que me- dida a posição ocupacional dos pais pode influenciar na escolha escola/trabalho. Acreditamos que a inclusão da posiçáo ocupacional dos pais na discussão referente à oferta de trabalho e à frequência escolar dos filhos deve contribuir substancialmente para uma melhor compreensão do ciclo intergeracional da pobreza.

O segundo assunto que merece maior atenção futura se refere aos fatores não explicáveis que contribuem para impedir que uma maior renda controlada das mães migrantes sem cônjuge não seja suficiente para reduzir a oferta precoce da mão de obra de seus filhos. Neste trabalho, levantamos a hipótese da relevância da distribuição ocupacional das mães. No entanto, essa suposição merece ser analisada de maneira mais detalhada.

Por último, este trabalho destaca indiretamente a importância do uso da escola como mecanismo de reversão do ciclo intergeracional da pobreza. Nesse sentido, o papel da escola na erradicação do trabalho infantil compreende duas ações simultâneas: ampliar o tempo de permanência da criança na escola, impedindo sua inserção no mercado de trabalho no curto prazo, e efetivar programas de transferência de renda às famílias, condicionada ao desempenho e permanência da criança na escola. 


\section{Referências}

AZÊVEDO, José Sergio Gabrielli; MENEZES, Wilson Antonio; FERNANDES, Claúdia M., Fora de lugar: crianças e adolescentes no mercado de trabalho. Coleção Teses \& Pesquisas: ABET, 2000.

BALAND, Jean-Marie; ROBINSON, James A., Is Child Labor Inefficient?, Journal of Political Economy, vol. 104, no. 4, 2000.

BARROS, Ricardo Paes; MENDONÇA, Rosane S. Pinto de. Determinantes da participação de menores na força de trabalho. Rio de Janeiro: IPEA, Texto Para Discussão, vol.200, 1990a.

BARROS, Ricardo Paes; MENDONÇA, Rosane S. Pinto de. Infância e adolescência no Brasil: as consequências da pobreza diferenciada por gênero, faixa etária e regiáo de residência. Rio de Janeiro: IPEA, Texto Para Discussäo, vol.202, 19906.

BASU, Kaushik; VAN, Pham Hoang, The economics of child labor, American Economic Review, v. 88, no. 3,1998 .

BASU, Kaushik; VAN, Pham Hoang; TZANNATOS, Zafiris, The Global child labor problem: what do we know and what can we do? World Bank Economic Review, vol. 17, 2003.
BILAC, Elisabete. D. Arranjos Domésticos e Condição Migratória. Em: PATARRA, Neide (Org.). Migração, condiçóes de vida e dinâmica urbana: São Paulo 1980-1993. Campinas: Ed. UNICAMP, 1997.

CERVINI, Ruben; BURGER, Freda. O Menor Trabalhador no Brasil. Em: FAUSTO, Ayrton; CERVINI, Ruben. O Trabalho e a Rua-Crianças e Adolescentes no Brasil Urbano dos Anos 80. Rio de Janeiro: Cortez, 1991.

CHISWICK, Barry R., The effect of Americanization on the earnings of foreign-born men, Journal of Political Economy, vol.86, n.5, 1978.

DaVANZO, Julie, Why families Move, RAND Corporation Report, September, 1976.

EMERSON, Patrick. M; SOUZA, André Portela, Is there a child labor trap? Intergenerational persistence of child labor in Brazil, Economic Development and Cultural Change, 51(2):37598, 2003.

FERREIRA-BATISTA, Natalia Nunes, Trabalho infantile migração no Estado de São Paulo, São Paulo, 2006. Tese de doutorado apresentada no Instituto de Pesquisas
Econômicas da Faculdade de Economia, Administração e Contabilidade - Universidade de São Paulo.

GREENE, William H.,

Econometric analysis, New Jersey: Prentice Hall, 1997.

GROOTAERT, Christian; KANBUR, Ravi, Child labor: an economic perspective, International Labour Review, vol. 134, no. 2, 1995.

JANNUZZI, Paulo M., Dinâmica migratória recente no interior paulista, Revista São Paulo em Perspectiva, v. 10, n. 2, 1996.

JANNUZZI, Paulo M.; Migração e mobilidade social: migrantes no mercado de trabalho paulista, Campinas, Autores

Associados, 2000.

KASSOUF, Ana Lúcia, Trabalho infantil no Brasil, Tese (Livre Docência), apresentada na Escola Superior de Agricultura Luiz de Queiroz da Universidade de São Paulo, Piracicaba: 1999.

LONG, Larry H., The influence of number and ages of children on residential mobility, Demography, n. 9,1972
LONG, Larry H., Does migration interfere with children's progress in school?, Sociology of Education, Michigan, n. 4, 1975.

MADDALA, Gangadharrao S., Limited-dependent and qualitative variables in econometrics, Cambridge: Cambridge University Press, 1986.

MARTINE, George. Adaptação dos migrantes ou sobrevivência dos mais fortes? In: MOURA, Helio A. de (coord.). Migraçẫo interna: textos selecionados. Fortaleza, BNB-ETENE, 1980.

MINCER, Jacob. Family Migration Decisions. Journal of Political Economy, 86:5, 1978.

MONTALI, Lilia. Família, Trabalho e Migração. Em: PATARRA, Neide (Org.). Migração, condiçōes de vida e dinâmica urbana: São Paulo 1980-1993. Campinas: Ed. UNICAMP, 1997.

MUNIZ, Jerônimo Oliveira, Uma aproximação empírica para o trabalho infantil no Brasil, Anais do VII Encontro Nacional da ABET, Salvador, 2001.

OAXACA, Ronald, Male-female wage differentials in urban labor markets, International Economic Review, vol.14, n. 4, 1973. 
PASTORE, José, Desigualdade e mobilidade social no Brasil, São

Paulo: T.A. Queiroz Editor, 1979.

ROSENZWEIG, Mark R.;

EVENSON Robert, Fertility,

schooling, and the economic contribution of children in rural

India: an econometric analysis, Econometrica, vol. 45, n.5, 1977.

SANDELL, Steven H., The economics of family migration, NLS Report on Dual Careers, vol. 4, 1975.

SANTOS JÚNIOR, Ernesto da Rosa, Migração e seleção: o caso do Brasil, Dissertação de Mestrado apresentada na Escola de Pósgraduação em Economia (EPGE) - FGV, Rio de Janeiro: FGV, 2002. Disponível em < http: //epge.fgv.br/portal/pesquisa/ producao/689 >. Acesso em 2/2/2004.

SILVEIRA NETO, Raul da Mota; MAGALHĀES, André Mato,

O progresso econômico do migrante me Sáo Paulo: evidências a partir dos censos demográficos de 1991 e 2000, III Encontro da Associaçấo Brasileira de Estudos Regionais - ABER, Belo Horizonte, 2004.

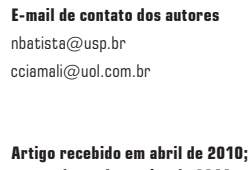




\section{Função verossimilhança e densidade conjunta do probit bivariado}

A função de verossimilhança do probit bivariado estimado é dada por:

$\ell\left(\beta_{1}, \beta_{2}\right)=\sum_{i=1}^{N}\left\{\ln \Phi_{2}\left(-\beta_{1} x_{1 i}, \beta_{2} x_{2 i},-\rho\right)+\ln \Phi_{2}\left(\beta_{1} x_{1 i}, \beta_{2} x_{2 i}, \rho \rho+\ln \Phi_{2}\left(\beta_{1} x_{1 i},-\beta_{2} x_{2 i},-\rho\right)+\ln \Phi_{2}\left(-\beta_{1} x_{1 i},-\beta_{2} x_{2 i}, \rho \rho\right)\right\}\right.$

I II III IV

Sendo: I. Só estuda, II. Estuda e trabalha, III. Só trabalha, IV. Não estuda e nem trabalha. A densidade conjunta dos erros normalmente distribuídos é dada por:

$$
\varphi\left(\mu_{1}, \mu_{2}\right)=\frac{1}{2 \pi \sigma_{\mu 1} \sigma_{\mu 2} \sqrt{1-\rho^{2}}} \exp \left[-\frac{1}{2}\left(\frac{\mu_{1}^{2}+\mu_{2}^{2}-2 \rho \mu_{1} \mu_{2}}{1-\rho^{2}}\right)\right]
$$




\section{Estatísticas descritivas das variáveis presentes no Probit bivariado}

Apêndice B

\section{Meninos - amostra família mesma condição de migração}

\begin{tabular}{|c|c|c|c|c|c|c|c|c|c|c|c|c|}
\hline \multirow[t]{2}{*}{ Variáveis } & \multicolumn{3}{|c|}{ Não migrante } & \multicolumn{3}{|c|}{ Migrante curto prazo } & \multicolumn{3}{|c|}{ Paulista Retornado } & \multicolumn{3}{|c|}{ Migrante longo prazo } \\
\hline & $\mathbf{N}$ & Média & DP & $\mathbf{N}$ & Média & DP & $\mathbf{N}$ & Média & DP & $\mathbf{N}$ & Média & DP \\
\hline Dummy estuda & 59.420 & 0,98 & 0,14 & 6.490 & 0,96 & 0,20 & 780 & 0,97 & 0,17 & 26.081 & 0,97 & 0,16 \\
\hline $\begin{array}{l}\text { Dummy } \\
\text { trabalha }\end{array}$ & 59.420 & 0,03 & 0,17 & 6.490 & 0,03 & 0,18 & 780 & 0,03 & 0,18 & 26.081 & 0,03 & 0,16 \\
\hline Idade & 59.420 & 12,00 & 1,41 & 6.490 & 11,90 & 1,40 & 780 & 11,95 & 1,42 & 26.081 & 12,04 & 1,41 \\
\hline Cor & 59.337 & 0,19 & 0,39 & 6.488 & 0,48 & 0,50 & 780 & 0,21 & 0,40 & 26.048 & 0,44 & 0,50 \\
\hline $\begin{array}{l}\text { Irmáos de } \\
0 \text { a } 9 \text { anos }\end{array}$ & 59.420 & 0,06 & 0,27 & 6.490 & 0,14 & 0,40 & 780 & 0,06 & 0,26 & 26.081 & 0,09 & 0,34 \\
\hline $\begin{array}{l}\text { Irmãos de } \\
15 \text { a } 17 \text { anos }\end{array}$ & 59.420 & 0,30 & 0,52 & 6.490 & 0,39 & 0,62 & 780 & 0,30 & 0,52 & 26.081 & 0,39 & 0,59 \\
\hline $\begin{array}{l}\text { Anos de } \\
\text { estudo - pai }\end{array}$ & 59.207 & 7,95 & 4,30 & 6.452 & 4,47 & 3,76 & 778 & 8,16 & 4,62 & 25.936 & 4,90 & 3,44 \\
\hline $\begin{array}{l}\text { Anos de } \\
\text { estudo - mãe }\end{array}$ & 59.176 & 7,71 & 4,18 & 6.451 & 4,80 & 3,65 & 779 & 7,76 & 4,34 & 25.936 & 4,95 & 3,33 \\
\hline $\mathrm{RPC}-\mathrm{NT}^{*}$ & 59.420 & 36,48 & 163,46 & 6.490 & 10,69 & 53,65 & 780 & 38,68 & 113,47 & 26.081 & 21,19 & 69,35 \\
\hline RMSP & 59.420 & 0,32 & 0,47 & 6.490 & 0,54 & 0,50 & 780 & 0,27 & 0,44 & 26.081 & 0,69 & 0,46 \\
\hline \% PEA agrícola & 59.420 & 8,21 & 11,32 & 6.490 & 3,80 & 8,17 & 780 & 7,88 & 10,48 & 26.081 & 2,45 & 6,57 \\
\hline $\mathrm{N}^{\circ}$. habitantes & 59.420 & $2,16 \mathrm{E}+05$ & $4,02 \mathrm{E}+05$ & 6.490 & $2,66 \mathrm{E}+05$ & $4,27 \mathrm{E}+05$ & 780 & $1,52 \mathrm{E}+05$ & $3,42 \mathrm{E}+05$ & 26.081 & $3,68 \mathrm{E}+05$ & $4,74 \mathrm{E}+05$ \\
\hline $\mathrm{IDH}-\mathrm{M}$ & 59.420 & 0,81 & 0,03 & 6.490 & 0,81 & 0,03 & 780 & 0,81 & 0,03 & 26.081 & 0,82 & 0,03 \\
\hline Válidos & 58.908 & & & 6.416 & & & 777 & & & 25.779 & & \\
\hline
\end{tabular}

$\mathrm{N}=\mathrm{n}^{\circ}$ de observaçốes $/ \mathrm{DP}=$ desvio padrão/ *RPC $-\mathrm{NT}=$ Renda familiar per capita do "não trabalho" 
Meninas - amostra família mesma condição de migração

\begin{tabular}{|c|c|c|c|c|c|c|c|c|c|c|c|c|}
\hline Variáveis & $\ddot{N}$ & $\begin{array}{l}0 \text { migran } \\
\text { Média }\end{array}$ & $\ddot{D P}$ & $\begin{array}{l}\mathbf{M i} \\
\mathbf{N}\end{array}$ & $\begin{array}{c}\text { nte curto } \\
\text { Média }\end{array}$ & Dp & $\dot{\mathbf{N}}$ & $\begin{array}{l}\text { sta Retor } \\
\text { Média }\end{array}$ & DP & $\cdots$ & $\begin{array}{c}\text { nte longo } \\
\text { Média }\end{array}$ & DP \\
\hline Dummy estuda & 56.868 & 0,98 & 0,13 & 6.108 & 0,96 & 0,20 & 784 & 0,99 & 0,11 & 25.294 & 0,98 & 0,15 \\
\hline $\begin{array}{l}\text { Dummy } \\
\text { trabalha }\end{array}$ & 56.868 & 0,02 & 0,14 & 6.108 & 0,02 & 0,15 & 784 & 0,01 & 0,11 & 25.294 & 0,02 & 0,13 \\
\hline Idade & 56.868 & 12,02 & 1,41 & 6.108 & 11,96 & 1,40 & 784 & 11,91 & 1,39 & 25.294 & 12,08 & 1,41 \\
\hline Cor & 56.800 & 0,19 & 0,39 & 6.103 & 0,47 & 0,50 & 784 & 0,20 & 0,40 & 25.264 & 0,42 & 0,49 \\
\hline $\begin{array}{l}\text { Irmáos de } \\
0 \text { a } 9 \text { anos }\end{array}$ & 56.868 & 0,06 & 0,27 & 6.108 & 0,14 & 0,40 & 784 & 0,05 & 0,22 & 25.294 & 0,09 & 0,33 \\
\hline $\begin{array}{l}\text { Irmãos de } \\
15 \text { a } 17 \text { anos }\end{array}$ & 56.868 & 0,31 & 0,53 & 6.108 & 0,38 & 0,61 & 784 & 0,31 & 0,54 & 25.294 & 0,40 & 0,60 \\
\hline $\begin{array}{l}\text { Anos de } \\
\text { estudo - pai }\end{array}$ & 56.690 & 7,91 & 4,30 & 6.058 & 4,30 & 3,67 & 783 & 7,97 & 4,58 & 25.160 & 4,85 & 3,38 \\
\hline $\begin{array}{l}\text { Anos de } \\
\text { estudo - mãe }\end{array}$ & 56.648 & 7,65 & 4,19 & 6.064 & 4,49 & 3,48 & 784 & 7,73 & 4,21 & 25.126 & 4,90 & 3,31 \\
\hline $\mathrm{RPC}-\mathrm{NT}^{*}$ & 56.868 & 35,54 & 146,90 & 6.108 & 10,82 & 59,41 & 784 & 28,83 & 106,53 & 25.294 & 22,60 & 80,74 \\
\hline RMSP & 56.868 & 0,32 & 0,47 & 6.108 & 0,55 & 0,50 & 784 & 0,28 & 0,45 & 25.294 & 0,69 & 0,46 \\
\hline \% PEA agrícola & 56.868 & 8,32 & 11,44 & 6.108 & 3,90 & 8,21 & 784 & 7,80 & 10,79 & 25.294 & 2,46 & 6,62 \\
\hline No. habitantes & 56.868 & $2,15 \mathrm{E}+05$ & $4,01 \mathrm{E}+05$ & 6.108 & $2,78 \mathrm{E}+05$ & $4,35 \mathrm{E}+05$ & 784 & $1,53 \mathrm{E}+05$ & $3,41 \mathrm{E}+05$ & 25.294 & $3,60 \mathrm{E}+05$ & $4,71 \mathrm{E}+05$ \\
\hline $\mathrm{IDH}-\mathrm{M}$ & 56.868 & 0,81 & 0,03 & 6.108 & 0,81 & 0,03 & 784 & 0,81 & 0,03 & 25.294 & 0,82 & 0,03 \\
\hline Válidos & 56.422 & & & 6.018 & & & 783 & & & 24.978 & & \\
\hline
\end{tabular}

$\mathrm{N}=\mathrm{n}^{\circ}$ de observaçóes / DP $=$ desvio padrăo $/$ *RPC $-\mathrm{NT}=$ Renda familiar per capita do "náo trabalho" 
Meninos - amostra mãe sem cônjuge

\begin{tabular}{|c|c|c|c|c|c|c|c|c|c|c|c|c|}
\hline \multirow[t]{2}{*}{ Variáveis } & \multicolumn{3}{|c|}{ Não migrante } & \multicolumn{3}{|c|}{ Migrante curto prazo } & \multicolumn{3}{|c|}{ Paulista Retornado } & \multicolumn{3}{|c|}{ Migrante longo prazo } \\
\hline & $\mathbf{N}$ & Média & DP & $\mathbf{N}$ & Média & DP & $\mathbf{N}$ & Média & DP & $\mathbf{N}$ & Média & DP \\
\hline Dummy estuda & 13.464 & 0,96 & 0,20 & 1.377 & 0,93 & 0,26 & 342 & 0,96 & 0,21 & 7.449 & 0,95 & 0,21 \\
\hline $\begin{array}{l}\text { Dummy } \\
\text { trabalha }\end{array}$ & 13.464 & 0,04 & 0,19 & 1.377 & 0,04 & 0,19 & 342 & 0,04 & 0,19 & 7.449 & 0,04 & 0,19 \\
\hline Idade & 13.464 & 12,08 & 1,41 & 1.377 & 12,11 & 1,41 & 342 & 11,97 & 1,42 & 7.449 & 12,15 & 1,41 \\
\hline Cor & 13.443 & 0,31 & 0,46 & 1.375 & 0,49 & 0,50 & 342 & 0,28 & 0,45 & 7.444 & 0,46 & 0,50 \\
\hline $\begin{array}{l}\text { Irmáos de } \\
0 \text { a } 9 \text { anos }\end{array}$ & 13.464 & 0,40 & 0,61 & 1.377 & 0,57 & 0,73 & 342 & 0,38 & 0,58 & 7.449 & 0,44 & 0,64 \\
\hline $\begin{array}{l}\text { Irmãos de } \\
15 \text { a } 17 \text { anos }\end{array}$ & 13.464 & 0,32 & 0,54 & 1.377 & 0,41 & 0,61 & 342 & 0,30 & 0,59 & 7.449 & 0,38 & 0,59 \\
\hline $\begin{array}{l}\text { Anos de } \\
\text { estudo - mâe }\end{array}$ & 13.389 & 7,21 & 4,17 & 1.369 & 4,83 & 3,78 & 340 & 7,22 & 4,26 & 7.392 & 5,02 & 3,62 \\
\hline $\mathrm{RPC}-\mathrm{NT}^{*}$ & 13.464 & 78,22 & 190,76 & 1.377 & 32,64 & 120,18 & 342 & 93,64 & 214,56 & 7.449 & 47,00 & 119,28 \\
\hline RMSP & 13.464 & 0,41 & 0,49 & 1.377 & 0,57 & 0,49 & 342 & 0,28 & 0,45 & 7.449 & 0,66 & 0,47 \\
\hline \% PEA agrícola & 13.464 & 6,48 & 10,22 & 1.377 & 3,62 & 7,90 & 342 & 8,20 & 11,41 & 7.449 & 3,07 & 7,58 \\
\hline No. habitantes & 13.464 & $2,74 \mathrm{E}+05$ & $4,39 \mathrm{E}+05$ & 1.377 & $3,10 \mathrm{E}+05$ & $4,52 \mathrm{E}+05$ & 342 & $1,45 \mathrm{E}+05$ & $3,37 \mathrm{E}+05$ & 7.449 & $3,85 \mathrm{E}+05$ & $4,82 \mathrm{E}+05$ \\
\hline IDH $-\mathrm{M}$ & 13.464 & 0,81 & 0,03 & 1.377 & 0,81 & 0,03 & 342 & 0,81 & 0,04 & 7.449 & 0,82 & 0,03 \\
\hline Válidos & 13.368 & & & 1.367 & & & 340 & & & 7.387 & & \\
\hline
\end{tabular}

$\mathrm{N}=\mathrm{n}^{\circ}$ de observaçóes $/ \mathrm{DP}=$ desvio padráo $/ * \mathrm{RPC}-\mathrm{NT}=$ Renda familiar per capita do "não trabalho" 
Meninas - amostra mãe sem cônjuge

\begin{tabular}{|c|c|c|c|c|c|c|c|c|c|c|c|c|}
\hline \multirow[t]{2}{*}{ Variáveis } & \multicolumn{3}{|c|}{ Não migrante } & \multicolumn{3}{|c|}{ Migrante curto prazo } & \multicolumn{3}{|c|}{ Paulista Retornado } & \multicolumn{3}{|c|}{ Migrante longo prazo } \\
\hline & $\mathbf{N}$ & Média & DP & $\mathbf{N}$ & Média & DP & $\mathbf{N}$ & Média & DP & $\mathbf{N}$ & Média & DP \\
\hline Dummy estuda & 13.534 & 0,97 & 0,17 & 1.640 & 0,94 & 0,24 & 336 & 0,97 & 0,16 & 7.494 & 0,96 & 0,19 \\
\hline $\begin{array}{l}\text { Dummy } \\
\text { trabalha }\end{array}$ & 13.534 & 0,03 & 0,16 & 1.640 & 0,03 & 0,18 & 336 & 0,05 & 0,21 & 7.494 & 0,03 & 0,17 \\
\hline Idade & 13.534 & 12,10 & 1,41 & 1.640 & 12,07 & 1,41 & 336 & 12,15 & 1,38 & 7.494 & 12,18 & 1,40 \\
\hline Cor & 13.522 & 0,29 & 0,45 & 1.636 & 0,46 & 0,50 & 336 & 0,28 & 0,45 & 7.488 & 0,43 & 0,50 \\
\hline $\begin{array}{l}\text { Irmâos de } \\
0 \text { a } 9 \text { anos }\end{array}$ & 13.534 & 0,39 & 0,60 & 1.640 & 0,55 & 0,72 & 336 & 0,38 & 0,53 & 7.494 & 0,44 & 0,63 \\
\hline $\begin{array}{l}\text { Irmãos de } \\
15 \text { a } 17 \text { anos }\end{array}$ & 13.534 & 0,31 & 0,53 & 1.640 & 0,38 & 0,59 & 336 & 0,32 & 0,55 & 7.494 & 0,37 & 0,58 \\
\hline $\begin{array}{l}\text { Anos de } \\
\text { estudo - mãe }\end{array}$ & 13.452 & 7,26 & 4,19 & 1.631 & 4,89 & 3,78 & 336 & 7,64 & 4,39 & 7.438 & 5,10 & 3,69 \\
\hline $\mathrm{RPC}-\mathrm{NT}^{*}$ & 13.534 & 79,93 & 193,49 & 1.640 & 30,70 & 129,12 & 336 & 71,07 & 127,42 & 7.494 & 49,39 & 140,55 \\
\hline RMSP & 13.534 & 0,40 & 0,49 & 1.640 & 0,61 & 0,49 & 336 & 0,30 & 0,46 & 7.494 & 0,66 & 0,47 \\
\hline \% PEA agrícola & 13.534 & 6,56 & 10,24 & 1.640 & 3,41 & 8,02 & 336 & 7,11 & 10,09 & 7.494 & 2,87 & 7,21 \\
\hline No. habitantes & 13.534 & $2,71 \mathrm{E}+05$ & $4,38 \mathrm{E}+05$ & 1.640 & $3,49 \mathrm{E}+05$ & $4,68 \mathrm{E}+05$ & 336 & $1,56 \mathrm{E}+05$ & $3,45 \mathrm{E}+05$ & 7.494 & $3,88 \mathrm{E}+05$ & $4,82 \mathrm{E}+05$ \\
\hline IDH $-\mathrm{M}$ & 13.534 & 0,81 & 0,03 & 1.640 & 0,82 & 0,03 & 336 & 0,81 & 0,03 & 7.494 & 0,82 & 0,03 \\
\hline Válidos & 13.440 & & & 1.627 & & & 336 & & & 7.432 & & \\
\hline
\end{tabular}

$\mathrm{N}=\mathrm{n}^{\circ}$ de observaçóes $/ \mathrm{DP}=$ desvio padrão $/$ *RPC $-\mathrm{NT}=$ Renda familiar per capita do "não trabalho" 
Relação entre tempo de residência do responsável pela família e idade dos filhos

Idade da criança no momento da migração

\begin{tabular}{|c|c|c|c|c|c|}
\hline \multirow{2}{*}{$\begin{array}{c}\text { Tempo de residência } \\
\text { no estado }\end{array}$} & \multicolumn{5}{|c|}{ Idade atual da criança } \\
\hline & 10 anos & 11 anos & 12 anos & 13 anos & 14 anos \\
\hline 0 & 10 & 11 & 12 & 13 & 14 \\
\hline 1 & 9 & 10 & 11 & 12 & 13 \\
\hline 2 & 8 & 9 & 10 & 11 & 12 \\
\hline 3 & 7 & 8 & 9 & 10 & 11 \\
\hline 4 & 6 & 7 & 8 & 9 & 10 \\
\hline 5 & 5 & 6 & 7 & 8 & 9 \\
\hline 6 & 4 & 5 & 6 & 7 & 8 \\
\hline 7 & 3 & 4 & 5 & 6 & 7 \\
\hline 8 & 2 & 3 & 4 & 5 & 6 \\
\hline 9 & 1 & 2 & 3 & 4 & 5 \\
\hline 10 & 0 & 1 & 2 & 3 & 4 \\
\hline 11 & 0 & 0 & 1 & 2 & 3 \\
\hline 12 & 0 & 0 & 0 & 1 & 2 \\
\hline 13 & 0 & 0 & 0 & 0 & 1 \\
\hline 14 & 0 & 0 & 0 & 0 & 0 \\
\hline 15 & 0 & 0 & 0 & 0 & 0 \\
\hline
\end{tabular}



